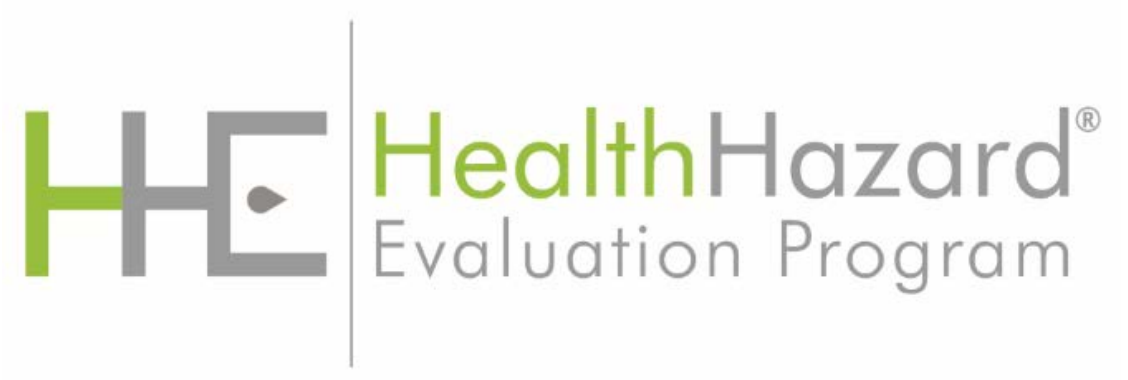

\title{
Evaluation of Exposures to Metals and Noise in a Boat Maintenance Facility
}

HHE Report No. 2017-0127-3348

April 2019

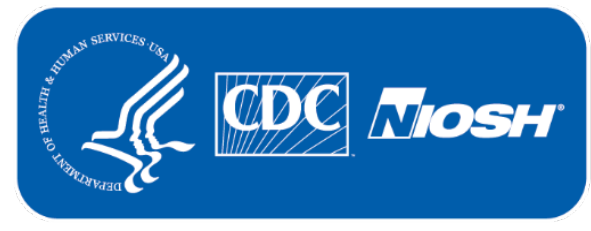




\section{Authors: $\quad$ Michael P. Grant, ScD}

\section{David A. Jackson, MD}

\section{Jennifer L. Topmiller, MS}

Analytical Support: Maxxam Analytics

Desktop Publisher: Jennifer Tyrawski

Editor: Cheryl Hamilton

Industrial Hygiene Field Assistance: Catherine Beaucham, Jessica Li, Michael Zhou

Logistics: Donnie Booher, Kevin Moore, Mihir Patel

Medical Field Assistance: Sarah Hatcher, Deborah Sammons

Keywords: North American Industry Classification System (NAICS) 926120 (Regulation and Administration of Transportation Programs), Massachusetts, Maintenance, Boat Maintenance, Welding, Metals, Chromium, Hexavalent Chromium, Manganese, Nickel, Noise, Hearing Protection, Ventilation

\section{Disclaimer}

The Health Hazard Evaluation Program investigates possible health hazards in the workplace under the authority of the Occupational Safety and Health Act of 1970 (29 U.S.C. \669(a)(6)). The Health Hazard Evaluation Program also provides, upon request, technical assistance to federal, state, and local agencies to investigate occupational health hazards and to prevent occupational disease or injury. Regulations guiding the Program can be found in Title 42, Code of Federal Regulations, Part 85; Requests for Health Hazard Evaluations (42 CFR Part 85).

\section{Availability of Report}

Copies of this report have been sent to the employer, employees, and union at the plant. The state and local health department and the Occupational Safety and Health Administration Regional Office have also received a copy. This report is not copyrighted and may be freely reproduced.

\section{Recommended Citation}

NIOSH [2019]. Evaluation of exposures to metals and noise at a boat maintenance facility. By Grant MP, Jackson DA, Topmiller JL. Cincinnati, OH: U.S. Department of Health and Human Services, Centers for Disease Control and Prevention, National Institute for Occupational Safety and Health, Health Hazard Evaluation Report 2017-0127-3348, https://www.cdc.gov/niosh/hhe/reports/pdfs/2017-0127-3348.pdf. 


\section{Main Report}

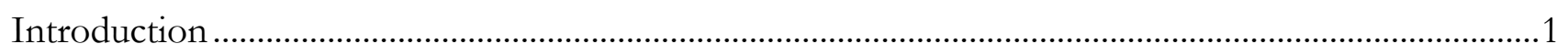

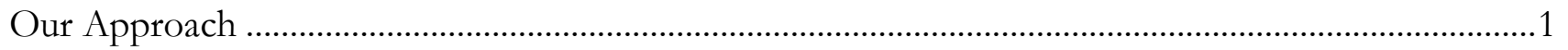

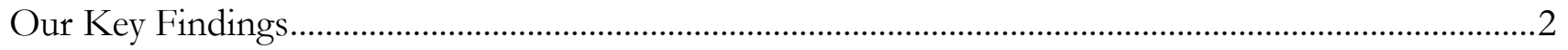

Our Recommendations .............................................................................................................

\section{Supporting Technical Information}

Section A: Workplace Information......................................................................................... A-1

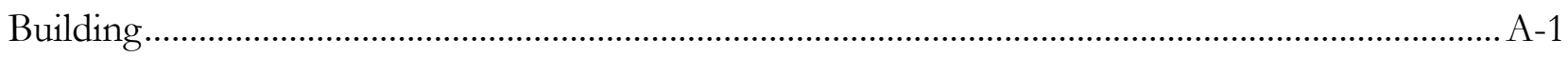

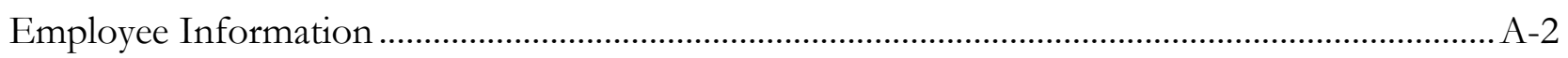

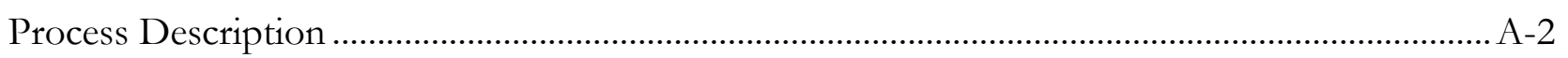

Section B: Methods, Results, and Discussion ……………………………………………..... B-1

Methods: Health and Safety Programs and Document Review ………………………………….... B-1

Results: Health and Safety Programs and Document Review ..................................................... B-1

Methods: Observations of Work Processes, Practices, and Conditions .......................................... B-4

Methods: Exposure Assessment ........................................................................................ B-6

Results: Exposure Assessment ................................................................................................ B-6

Methods: Ventilation Assessment.......................................................................................... B-7

Results: Ventilation Assessment....................................................................................... B-8

Methods: Employee Health Assessment and Biomonitoring ............................................................. B-9

Results: Employee Health Assessment and Biomonitoring …………………………………..... B-10

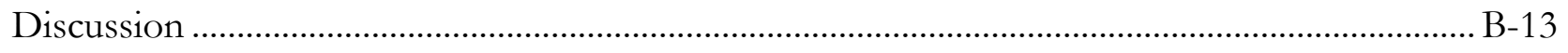

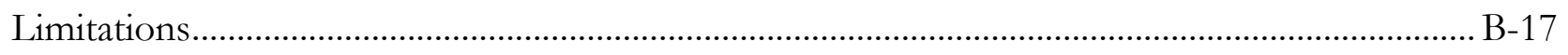

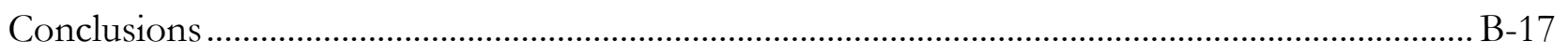

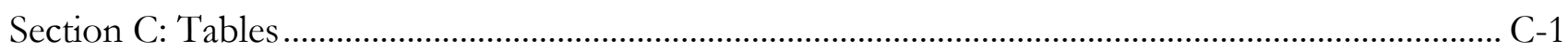

Section D: Occupational Exposure Limits .............................................................................

Chromium and Hexavalent Chromium ………………………………………………….. D-2

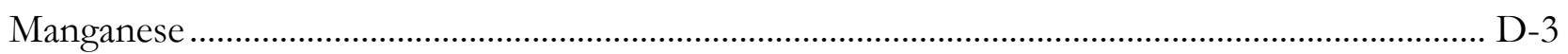

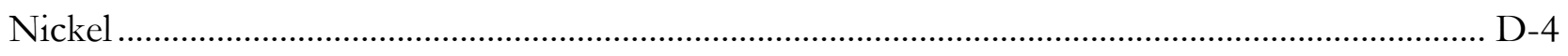

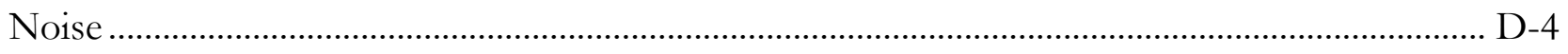

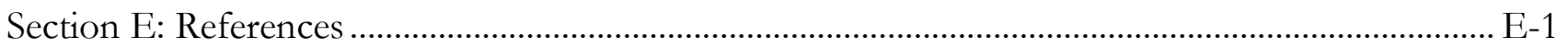


This page left intentionally blank 


\section{Introduction}

\section{Request}

We received a request from management at a boat maintenance facility concerned about employees' occupational exposures during work in several types of industrial shops.

\section{Workplace}

The facility consisted of a large boat bay with several shops situated in and around it. The shops included the welder shop, ship fitter shop, machinist shop, marine mechanic shop, pipe fitter shop, electrician shop, and the carpenter/boat builder shop.

We made two visits to the facility. At the time of our second visit, 26 employees worked across the seven shops. Most employees belonged to the union. The facility had one work shift per day, Monday through Friday. Employees worked 8-10 hours per day, 4-5 days per week. The amount of work performed in the facility during our second visit was reported to be less than typically expected. The first day of this visit was primarily a cleaning day. No carpenter/boat builder work was performed during this visit.

To learn more about the workplace, go to Section A in the Supporting Technical Information

\section{Our Approach}

We visited the facility twice to learn more about health concerns and to measure exposures. On our site visits we

- Reviewed the facility health and safety programs and documents

- Observed work processes, work practices, and workplace conditions

- Measured employee exposures to metals, in air and on surfaces, and noise

- Assessed the local exhaust and general ventilation systems

- Held confidential medical interviews, administered medical questionnaires, performed nasal examinations, and tested urine for nickel, chromium, and manganese

To learn more about our methods, go to Section B in the Supporting Technical Information 


\section{Our Key Findings}

\section{Employees were exposed to noise levels above the National Institute for Occupational Safety and Health (NIOSH) recommended exposure limit}

- One welder and one pipe fitter were exposed to noise levels above the NIOSH recommended exposure limit for noise even though the work performed during our visit was less than normal.

- All employees were exposed to noise levels below the Occupational Safety and Health Administration (OSHA) action level and permissible exposure limit for noise.

- Spot noise measurements taken 10-15 feet from drill saw activity ranged from 80-83.5 decibels, A-weighted. This level is just below the NIOSH recommended exposure limit for noise of 85 decibels, A-weighted. The worker using the drill likely had noise exposures substantially higher than what we measured $10-15$ feet away.

\section{Work practices and conditions contributed to noise exposures}

- Welder, ship fitter, marine mechanic, pipe fitter, and carpenter/boat builder shop employees were included in the facility's hearing conservation program.

0 Although the hearing conservation program required annual hearing testing (i.e., audiometry) of all enrolled employees, audiometry records were not available for all employees of these shops.

o Twelve employees reported symptoms commonly associated with hearing loss, such as ringing or buzzing in the ears or trouble hearing clearly or fully. Audiometry records were not available for 9 of these 12 employees.

o Medical records indicated that one employee's hearing loss was the result of exposure to noise at the facility.

- Specific written plans for hearing protection requirements, such as what activities require hearing protection or the types of hearing protection required, were not available.

- Employees reported difficulty accessing ear plugs from the ear plug dispenser even when the dispenser appeared full.

- We did not observe many workers wearing hearing protection, even when they were working close to or using loud tools.

\section{Employees were exposed to metals in the workplace}

- All of the full-shift personal air sampling results for metals were below the lowest occupational exposure limit.

- We detected low levels of a variety of metals in personal air samples and on surface wipe samples in the facility's break and production areas. 
- One employee was exposed to airborne nickel levels just below the NIOSH recommended exposure limit.

- Two employees had urine nickel levels above the normal general population level.

- Several work practices were identified that may have contributed to exposures.

Communication gaps existed between employees, the union, management, and clinic staff performing medical surveillance evaluations

- Employees reported a lack of communication between shops about the many different job tasks being concurrently performed in the boat bay.

- Employees perceived a lack of response and acknowledgement of concerns on health and safety matters from management representatives.

- Employees and management expressed uncertainty as to when the local exhaust ventilation system filters were last changed. Employees did not know who was responsible for maintenance and filter changes.

- Employees felt they had received inadequate health and safety training.

- Chromium medical evaluation records were not available for employees in the welder, ship fitter, and pipe fitter shops, although management reported that those employees were enrolled in the facility's chromium medical surveillance program.

To learn more about our results, go to Section B in the Supporting Technical Information

\section{Our Recommendations}

The Occupational Safety and Health Act requires employers to provide a safe workplace.

\section{Benefits of Improving Workplace Health and Safety:}
个 Improved worker health and well-being
个 Improved image and reputation
个 Better workplace morale
个 Better products, processes, and services
个 Better employee recruiting and retention
$\uparrow$ Could increase overall cost savings

The recommendations below are based on the findings of our evaluation. For each recommendation, we list a series of actions you can take to address the issue at your workplace. The actions at the beginning of each list are preferable to the ones listed later. The list order is based on a well-accepted approach called the "hierarchy of controls." The hierarchy of controls groups actions by their likely effectiveness in reducing or removing hazards. In most cases, the preferred approach is to eliminate hazardous materials or processes and install engineering controls to reduce exposure or shield 
employees. Until such controls are in place, or if they are not effective or feasible, administrative measures and personal protective equipment might be needed. Read more about the hierarchy of controls: https://www.cdc.gov/niosh/topics/hierarchy/.

We encourage the company to use a health and safety committee to discuss our recommendations and develop an action plan. Both employee representatives and management representatives should be included on the committee. Helpful guidance can be found in "Recommended Practices for Safety and Health Programs":

https://www.osha.gov/shpguidelines/index.html.

\section{Recommendation 1: Reduce employees' exposure to noise}

Why? Noise-induced hearing loss is an irreversible condition that progresses with noise exposure. Unlike some other types of hearing disorders, noise-induced hearing loss cannot be treated medically. Noise-exposed workers can develop substantial noise-induced hearing loss before it is clearly recognized. Even mild hearing loss can impair a person's ability to understand speech and hear many important sounds. In addition, some people with noise-induced hearing loss also develop tinnitus, a condition in which a person perceives a ringing, hissing, buzzing, or whistling sound even though no external sound is present. Currently, there is no cure for tinnitus. Noise-induced hearing loss symptoms can worsen over time and could be associated with the following:

- More sick leave

- Job loss

- Lower quality of life

We found two employees exposed to noise levels above the NIOSH recommended exposure limit for noise. On days when employees perform more work activities, noise exposures could be even higher. Of the 19 employees who completed a questionnaire, 12 reported tinnitus and/or trouble hearing clearly.

How? At your workplace, we recommend these specific actions:

\section{Perform a comprehensive noise assessment during a workday when typical levels of work are occurring.}

- Based on the results of the comprehensive noise assessment, consider consulting with a noise control engineer on options to reduce employees' noise exposure. Noise control options include constructing barriers or enclosures around equipment or equipment operators. 
- Post clearly visible signs at the entrance to areas where noise exposures are high, warning facility employees of noise exposures, hearing hazards, and hearing protection requirements.

- Repeat the noise assessment when processes change or new equipment is installed. Consider performing periodic noise assessments, as production activities can vary over time depending on the type of work requested for each job.

- Work with the facility health and safety committee to review and update written hearing protection plans for the facility based on the noise assessment results. Discuss the noise monitoring plan at meetings to determine when repeat monitoring should occur.

- Ensure that adequate supplies of appropriate personal hearing protectors, such as ear plugs and ear muffs, are always available for employees to use when performing tasks or working in areas where noise levels are high.

\section{Thoroughly review and update as needed the facility hearing conservation program including these guidelines:}

- Ensure that all employees enrolled in the program receive baseline and annual audiograms, and maintain these records.

- Evaluate audiograms using the NIOSH criteria for identifying standard threshold shifts, which are significant changes from baseline hearing audiograms. The NIOSH criteria are more protective than OSHA criteria and will provide earlier identification of employees with hearing loss.

- Request that the audiometric test provider not age correct when evaluating audiograms.

- Educate employees on noise exposures. Give them information related to hearing hazards and hearing protection requirements, including locations and processes that require hearing protection (based on the comprehensive noise assessment).

- Instruct employees to promptly report any symptoms possibly related to workplace noise exposure, such as trouble hearing clearly, or ringing or buzzing in the ears and track such reports. Encourage employees with possible work-related hearing concerns to seek medical care from qualified healthcare professionals. Include these reports in safety committee meetings. Discuss action items and provide updates on past reports as needed. 


\section{Recommendation 2: Reduce employees' exposures to nickel and other metals}

Why? Overexposure to nickel can have harmful effects. Allergic reactions from direct skin contact with nickel, like a rash at the site of nickel contact, are the most common harmful health effects in humans. Inhalation of nickel-containing dust and fumes may cause asthma attacks in workers who are sensitized to nickel and can lead to chronic bronchitis or reduced lung function over time. Nickel is also considered a cancer-causing agent, with chronic overexposures leading to nasal, sinus, and lung cancers. Health effects resulting from overexposure to nickel could result in

- More sick leave

- Job loss

- Lower quality of life

We found two employees with urine nickel levels greater than the normal general population urine nickel level. Although personal airborne nickel exposures were below occupational exposure limits, one employee was exposed to airborne nickel levels that were only slightly below the NIOSH recommended exposure limit for nickel. On days when more work activities are performed, nickel exposures could be even higher. Inconsistent handwashing, dry sweeping, and eating and drinking in work areas may have contributed to unnecessary nickel exposures through inhalation and ingestion.

\section{How? At your workplace, we recommend these specific actions:}

\section{Require all employees to wash their hands before eating, drinking, or smoking, and each time they leave the workplace.}

- Educate employees about the importance of handwashing to remove contaminants like nickel from their hands to reduce the risk of absorbing the contaminants into the body.

- Offer smoking cessation programs at no cost to employees. Encourage employees who smoke to participate in smoking cessation programs. Smoking cessation may decrease nickel exposure and symptoms worsened by workplace exposures.

\section{Do not allow employees to consume or store food or drink in work areas.}

- Separate group water stations from production (work) areas by placing them behind closed doors in nonproduction areas.

- Ensure that employees have adequate break areas - separated from production areas by closed doors_-for eating, drinking, and storing food.

- Isolate areas like the pipe fitter shop break room with floor to ceiling walls to prevent contaminant migration from production to nonproduction areas. 


\section{Review and update cleaning protocols to keep surfaces as free as practicable of contaminants.}

- Use wet cleaning methods or a vacuum equipped with a high efficiency particulate air filter for cleaning contaminated surfaces.

- Do not dry sweep dust, and do not use compressed air for cleaning. Compressed air should never be used to clean up workplace dusts.

- Provide, at a minimum, annual training to ensure compliance with approved cleaning practices.

\section{Encourage employees with possible work-related health concerns to talk to their healthcare providers about their workplace exposures to metals, such as nickel.}

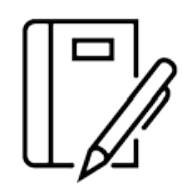

\section{Review and update personal protective equipment plans for all shops.}

- Review tasks, tools, and procedures used in all shops.

- Use the safety committee to create personal protective equipment (PPE) plans for each shop and job task.

- Communicate relevant PPE requirements to employees. Provide periodic training to ensure compliance with approved PPE plans.

Recommendation 3: Improve communication between employees, the union, and management in response to employee health and safety concerns

Why? Employees' health can be affected by a perceived lack of response to concerns, especially if employees believe that an exposure is hazardous and have negative attitudes toward the exposure. We identified several communication issues at the facility during our evaluation. Employees reported a lack of communication between shops at times about the job tasks being performed in the boat bay. Employees expressed concern that this lack of communication prevented them from taking necessary actions to prevent or reduce exposures. Employees also reported a perceived lack of response and acknowledgement of concerns on health and safety matters from management representatives. There was uncertainty from employees and management as to when the local exhaust ventilation system filters were last changed. There was confusion among employees about who was responsible for maintenance and filter changes. 
How? At your workplace, we recommend these specific actions:

Include employee, union, and employer representatives in the existing health and safety committee to encourage effective communication and problem solving.

- Work with the health and safety committee to discuss workplace concerns and develop action plans for continued improvement of employee health and safety.

Ensure that a formal procedure is in place to report and document health and safety concerns.

- Ensure that there is a process available to employees for submitting a confidential report.

- Reassure employees that they can submit a confidential report.

- Listen actively to employees' concerns in a nonjudgmental way. Employees should feel that their concerns are taken seriously.

- Inform employees of the steps taken to assess problems, including what is known and what remains to be determined. A combination of written reports and face-to-face meetings are effective for communicating to employees.

- Share information regularly with employees rather than waiting until a cause of the problem in discovered; this will reduce the chance of distorted rumors.

Work with the healthcare providers who perform employee medical surveillance evaluations to ensure they are up-to-date on all policies and requirements. 


\section{Recommendation 4: Address other health and safety issues we identified during our evaluation}

Why? A workplace can have multiple health hazards that cause worker illness or injury. Similar to the ones identified above, these hazards can potentially cause serious health symptoms, lower morale and quality of life for your employees, and increase costs to your business. We saw the following potential issues at your workplace:

- Inefficient local exhaust ventilation system.

- Lack of a written plan for local exhaust ventilation system maintenance.

- Risk of injury to people walking through the boat bay in improper attire. We observed multiple people passing through the boat bay to other areas of the facility wearing inappropriate attire (e.g., shorts and sandals) for production areas.

- Lack of barriers to limit access when work is occurring in the boat bay. We observed employees walking through the boat bay close to where work was being performed.

- Lack of enforcement of respiratory protection program requirements. For example, we observed employees with facial hair wearing respirators.

Although these hazards were not the focus of our evaluation, they could cause harm to your workers' health and safety and should be addressed.

How? At your workplace, we recommend these specific actions:

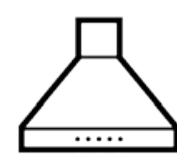

\{\}

\section{Improve local exhaust ventilation systems.}

- Remove unnecessary "dead legs" (lengths of duct not serving any active machinery) and unused ducting.

- Minimize 90-degree turns and flexible ducting.

- Limit the use of personal cooling fans. There were several fans in use that could disrupt the effectiveness of the local exhaust ventilation systems. If they are necessary for comfort, air showers that direct air from above are a better solution.

- Repair the ventilation in the hose cutting room. Consider enclosing the process to improve the efficiency of smoke removal.

- Repair the electrostatic filters in the general ventilation system.

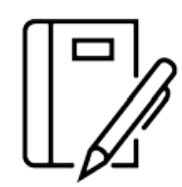

\section{Create a written local exhaust ventilation system maintenance plan.}

- Include information about who is responsible for various aspects of maintenance and troubleshooting. 
- Communicate pertinent information to employees so that they know who to contact if there are concerns about the local exhaust ventilation system performance.

- Provide periodic training and updates to employees to ensure awareness of the contents of the written plan.

\section{Ensure people walk through the boat bay in proper attire.}

- Work with people or departments to determine the best way to avoid this issue moving forward. Either provide a different path so people avoid walking through the boat bay at all or make certain that they wear appropriate attire when they do.

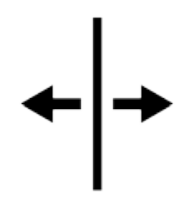

\section{Limit access to the boat bay when work is occurring.}

- Divert foot traffic away from the boat bay to reduce potential exposures for people not engaged in the work.

\section{Enforce requirements for the existing respiratory protection program.}

- Tell employees to keep the same facial hair style during respirator fit testing that they intend to have when wearing respirators while working.

- Ensure that employees do not have facial hair that can interfere with the sealing surface of tight-fitting respirators. 


\section{Supporting Technic al Information}

Evaluation of Exposures to Metals and Noise in a Boat Maintenance Facility

HHE Report No. 2017-0127-3348

April 2019 
This page left intentionally blank 


\section{Section A: Workplace Information}

\section{Building}

- The facility (Figure A1) contained a boat bay, and a variety of shops, a hose room, offices, and break areas surrounding the boat bay. The boat bay can fit two boats side-by-side. During our second visit, there was one 25 -foot and one 49-foot boat in the boat bay.

- One end of the boat bay had a large roll-up overhead door. Employees used this door to transfer boats, equipment, and materials in and out of the building.

- Several shops opened into the boat bay: the welder shop, ship fitter shop, and machinist shop located on the north side and the carpenter/boat builder shop on the south side of the boat bay.

- The marine mechanic shop sat at the back or west side of the boat bay with no separation between the shop and the boat bay.

- Because there was no separation between the welder and ship fitter shops, the space where the welders and ship fitters worked was called the metal shop. The metal shop was one story high and opened on one side into the boat bay.

- The machinist shop was separated from the boat bay by a door that remained open throughout the workday.

- The carpenter/boat builder shop had a roll-up overhead door that could be closed to separate it from the boat bay. Employees reported that this door remained open throughout the workday.

- The pipe fitter and electrician shops were also on the north side of the boat bay, but a hallway separated them from the boat bay and the other shops.

- Additional office space was located on the second floor of the building on the north side of the boat bay. This space was separated from the boat bay by doors that were usually closed. 


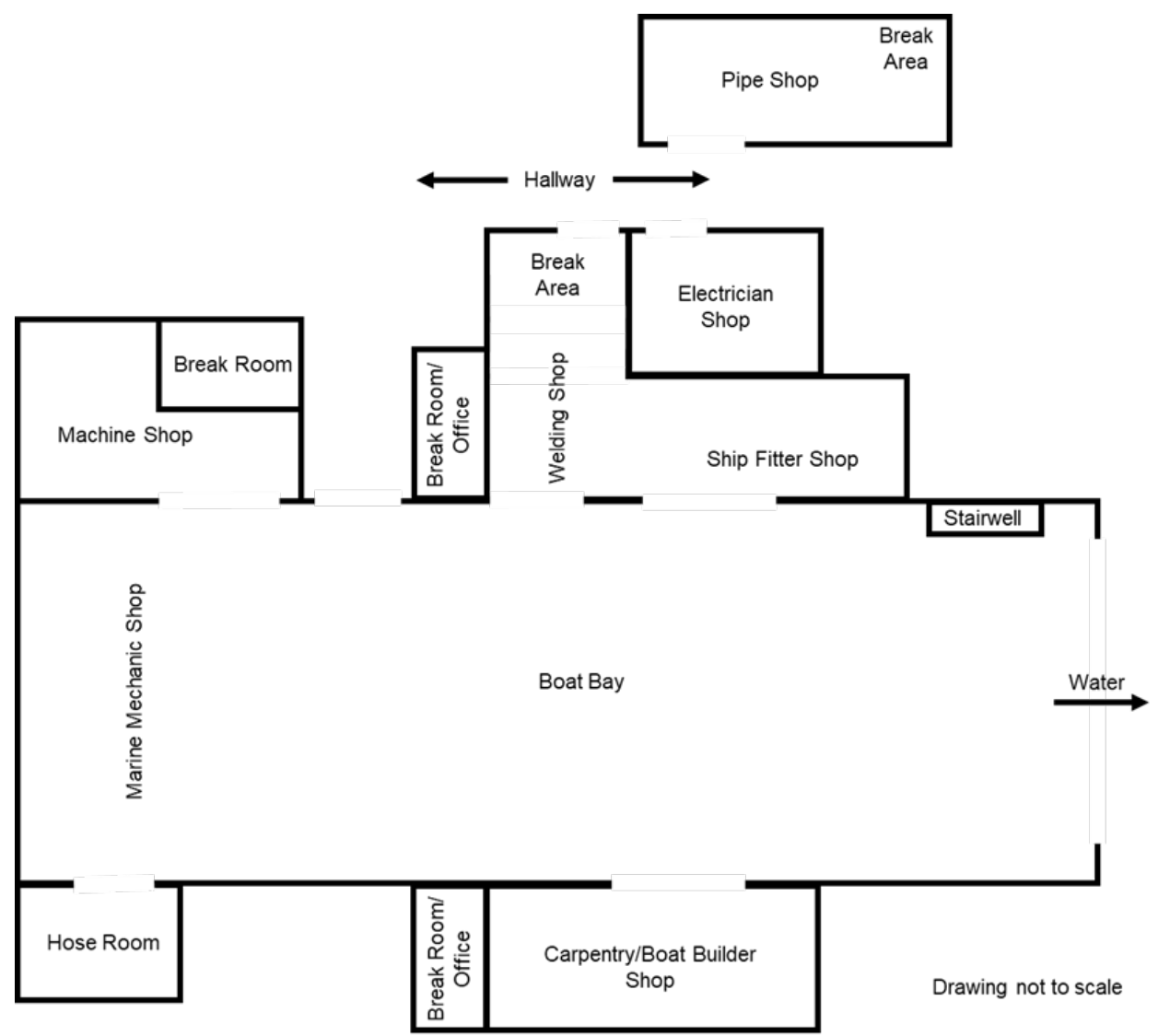

Figure A1. Diagram of the boat bay and surrounding shops. Figure by NIOSH.

\section{Employee Information}

- In total, 26 employees worked across the welder, ship fitter, machinist, marine mechanic, pipe fitter, electrician, and carpenter/boat builder shops. Most employees belonged to a union.

- The facility operated a single shift Monday through Friday, and employees worked 8-10 hours per day. The length of the workweek ranged from 4-5 days depending on each employee's schedule.

- The median age of employees was 53 years (range: 32-66 years).

- The median job tenure was 10 years (range: 11 months-22 years).

\section{Process Description}

- The work performed by the shops varied according to the needs of the boats being serviced.

- At the time of our second visit, there were two boats being serviced inside the boat bay and two boats docked outside of the facility. Employees from each shop worked as needed to complete the maintenance required by each boat.

- Employees spent their workday in a combination of areas: the shops within the facility, the boat bay (either around or onboard the boats), the boats docked behind the facility (either above or below deck), and the break area(s). 


\section{Section B: Methods, Results, and Discussion}

Our objectives were to

- Evaluate the routes and extent of exposures to metals and noise among employees from the welder, ship fitter, machinist, marine mechanic, pipe fitter, electrician, and carpenter/boat builder shops

- Evaluate the effectiveness of the local exhaust ventilation system for controlling metal exposures

- Determine the prevalence of elevated urine nickel, chromium, and manganese levels among employees and evaluate for factors that may contribute to elevated urine metal levels

- Determine the prevalence of work-related skin, respiratory, and hearing loss symptoms and other health effects among employees and evaluate for factors that may contribute to these symptoms and health effects

\section{Methods: Health and Safety Programs and Document Review}

We reviewed the facility's written chromium medical surveillance program, respiratory protection program, and hearing conservation program. We also reviewed the results of three prior environmental evaluations at the facility: an internal indoor environmental quality assessment completed in 2017, surface wipe sampling completed in 2016, and a welding assessment completed in 2015. In addition, we reviewed facility safety checklists, safety data sheets, OSHA Form 300 Log of Work-Related Injuries and Illnesses for the period of 1/1/2012-12/15/2017, and facility floor plans.

We also reviewed all available medical records related to the facility's chromium medical surveillance program, respiratory protection program, and hearing conservation program for the period of 1/1/2013-6/6/2018. Facility management told us that all employees of the welder, ship fitter, marine mechanic, pipe fitter, and carpenter/boat builder shops were included in the hearing conservation and respiratory protection programs, and that all employees of the welder, ship fitter, and pipe fitter shops were included in the chromium medical surveillance program. We also reviewed relevant employee medical records related to care received for hearing and respiratory symptoms experienced at work.

\section{Results: Health and Safety Programs and Document Review}

According to the facility's written chromium medical surveillance program dated $2 / 27 / 2017$, any personnel who may be exposed to air concentrations of hexavalent chromium compounds at or above the American Conference of Governmental Industrial Hygienists $\left(\mathrm{ACGIH}^{\circledR}\right)$ threshold limit value $\left(\mathrm{TLV}^{\circledR}\right)$ must be included in the program. Employees included in the program must undergo initial, periodic, and exit examinations that include a history; physical examination; laboratory testing that includes a complete blood count, multichemistry panel, and a urinalysis with microscopy; pulmonary function testing; a posterior-anterior view chest radiograph for initial and exit examinations; and any other tests that are clinically indicated. The periodic examinations must be provided annually unless a healthcare provider recommends a longer interval. Although not included in the written chromium 
medical surveillance program, facility management told us that employees enrolled in the program also undergo annual blood testing for chromium.

Facility management informed us that enrollment in the chromium medical surveillance program was based on how frequently employees in the welder, ship fitter, and pipe fitter shops work with chromium compounds. Still, the wide variation in the type of work these shops perform with these substances makes assessment of all possible exposure scenarios very challenging. However, the clinic that performs these medical surveillance evaluations and maintains the medical records for any medical surveillance testing done elsewhere did not have any record of chromium medical surveillance evaluations for any of the employees who worked at the facility over the period of $1 / 1 / 2013-6 / 6 / 2018$. The clinic, operated by the facility, is located onsite in a separate building adjacent to the boat bay. When a history and physical examination were available, the healthcare providers performing the evaluations stated these employees were only enrolled in the facility's hearing conservation and respiratory protection medical surveillance programs.

Seven employees had at least one pulmonary function test result over the period evaluated. Chromium compounds were listed as an exposure on one of the pulmonary function test results we reviewed. For the other pulmonary function test results, the documentation we reviewed either did not provide an easily identifiable indication or noted that the testing was being performed as a part of the employee's respirator medical clearance.

Although the pulmonary function testing for three employees showed reduced ratios of forced expiratory volume in one second to forced vital capacity, no history or post-bronchodilator pulmonary function testing was available to allow for differentiation between reversible obstructive lung disease, such as asthma, and fixed obstructive lung disease, such as chronic obstructive pulmonary disease. Pulmonary function testing results reviewed for the remaining four employees were normal. Based on employee medical record review for care received for respiratory symptoms that began while working at the facility, one employee was treated for two episodes of pneumonia, once in 2013 and once in 2014. These records did not mention the employee's work-related exposures or attribute the pneumonias to exposures experienced at work.

As a part of the facility's hearing conservation program, all employees enrolled in the program should receive baseline, periodic (at least annual), and exit audiograms. Although facility management told us that all welder, ship fitter, marine mechanic, pipe fitter, and carpenter/boat builder shop employees were included in the hearing conservation program, the clinic where the audiograms are performed only had audiogram results for 13 of 24 employees from these shops over the period of 1/1/2013-6/6/2018. Only seven of these employees had testing performed within 24 months of the date we received the records. Three employees had audiogram test results suggestive of a standard threshold shift (STS) hearing loss on one or more of their audiograms. However, we did not have enough information from the records provided to confirm whether these results satisfied OSHA or NIOSH STS criteria. Based on employee medical record review for care received for hearing loss that began while working at the facility, one employee was reported by the evaluating physician to have significant high frequency hearing loss that was "greater than what would be expected from 
presbycusis" in both ears. The physician determined that this employee's hearing loss "is noise induced as a result of exposure to noise" while working at the facility.

Review of the OSHA $300 \operatorname{logs}$ for the period of 1/1/2012-12/15/2017 demonstrated a variety of injuries and illnesses ranging from 2-19 incidences reported per year over this time. Most of the injuries and illnesses included in the logs were minor in nature, such as bruises, strains, and sprains. In July of 2015, three entries described as "absorption, internal organs" and three entries described as "ingestion, internal organs" were noted. All six of these entries were labeled as "poisoning" in the type of illness section of the logs. Further details or information about these incidents was not available.

There are three main types of metal that are welded in this facility: two types of alloy steel and a stainless steel. Review of the safety data sheets showed the major components of these metals to be aluminum, chromium, copper, iron, magnesium, manganese, molybdenum, and nickel. Past air sampling performed at the facility demonstrated elevated levels of airborne manganese during certain job tasks. Besides being a component of some of the metal alloys welded at the facility, nickel is a major component of the copper-nickel pipe commonly used by the pipe fitters.

Review of personal sampling results in 2015 showed an overexposure to manganese during welding tasks. The 2015 assessment used short-term samples (54-240 minutes) to calculate full-shift exposures. The time that was not sampled was assumed to be zero concentration. Summarized results from surface wipe sampling completed in 2016 revealed significant metal dust contamination in nonindustrial areas of the facility (i.e., break room surfaces). In 2017, the indoor environmental quality assessment showed temperature, carbon monoxide, and carbon dioxide levels within acceptable parameters. Relative humidity was lower than the acceptable range but not considered abnormal given outdoor ambient relative humidity. All area air samples taken in the boat bay and analyzed for various elements by NIOSH Method 7303 were found to have nondetectable concentrations.

Reviewing internal annual facility safety checklists for 2016 and 2017 did not reveal anything out of the ordinary. The facility self-reported that it was in compliance with applicable internal and OSHA regulatory requirements.

Internal company regulations require written PPE plans. These plans should outline what equipment is necessary for different tasks and locations within the facility. According to annual internal safety audits performed in 2016 and 2017, this facility has PPE plans and meets the internal regulation. We were not able to access these plans during or after our visits to the facility. We have been informed that the site health and safety committee is working on these documents presently.

We reviewed internal communications related to the 2015 welding assessment. In these, the industrial hygienist who performed the assessment recommended at least single hearing protection for all nearby employees in areas where grinding or welding were being performed. Double hearing protection was recommended for all nearby employees in areas where needle gunning or plasma cutting were being performed. These communications also advised that welders and those working nearby be required to wear half-mask elastomeric respirators with P100 cartridges when welding on or below deck on boats, including all employees working below deck when below deck welding operations were occurring. We were not able to confirm if these recommendations were implemented. 


\section{Methods: Observations of Work Processes, Practices, and Conditions}

We evaluated the following in the welder, ship fitter, machinist, marine mechanic, pipe fitter, electrician, and carpenter/boat builder shops as well as the boat bay in general:

- Work processes

- Work practices, such as employee use of PPE

- Workplace conditions

\section{Results: Observations of Work Processes, Practices, and Conditions}

- Employees were required to wear eye protection when in the shops and boat bay. We observed that most employees wore safety glasses most of the time they were in the boat bay. Some employees wore welding face shields when welding.

- We observed pedestal fans located around the marine mechanic shop. The fans near occupied workstations were in use while we were at the facility and were mostly directed towards the boat bay doors. Some other shops also had pedestal fans that were not in use.

- Housekeeping was generally good with respect to floors but work benches and some areas of the floor in the boat bay were visibly covered in dust. We were informed that the amount of work performed in the facility during our second visit was less than typically expected. One of the days that we were there was primarily a cleaning day and no carpenter/boat builder work was performed during our visit. We did not sample for wood dust because no woodworking occurred during our visit. We also did not observe cleaning practices at the end of a typical workday as employees did not work a typical workday during our visit.

- Break rooms were located within or adjacent to most work areas. In the pipe fitter shop, the break and office areas were located above the shop without walls or doors to separate the work area from the break area. There was an office area adjacent to the welder and ship fitter shops that was a separate room with a door. There was an office area adjacent to the carpenter/boat builder shop that was a separate room with a door. Adjacent to the machinist shop there was a break area used by employees from the machinist, marine mechanic, and electrician shops. A training and break room was located on the second floor of the building, on the north side of the boat bay. This room was separated from the boat bay by some offices and a hallway.

- We saw drinks on work benches and in work areas but did not see employees actively eating or drinking in production areas of the shops.

- No requirement existed for additional PPE for bystanders, and no barriers were set up to divert or prevent employees from walking by work being performed in the boat bay. We observed individuals who were not assigned to work in the boat bay passing through to other areas of the facility without wearing PPE. We observed some of these individuals wearing sandals in the boat bay.

- We observed improper use of the local exhaust ventilation system in the pipe fitter shop. The articulating arms were secured above the workstations and not pulled down near where the work 
was being performed. In the welder shop, we observed some employees positioning the local exhaust system articulating arm near the welds being performed. Other employees were not utilizing the local exhaust ventilation system when performing tungsten inert gas (TIG) welding.

- We asked a number of employees and managers about the local exhaust ventilation systems and found confusion about maintenance responsibilities. We were not able to discern who was responsible for maintenance activities (i.e., changing filters). We were not able to find a written filter change-out plan.

- We observed an employee who demonstrated cutting wire-reinforced hose in the hose room. Employees reported that they could spend up to a half day each week cutting all of the hose that was needed for the week, although we observed no other hose cutting work during our visit. Employees were uncertain of the PPE requirements for this job task. The hose room, which was about two stories high, had a ventilation fan in the ceiling. The fan intake was broken, and employees had inserted a long pole into the opening to prop open the louvers. Even though the fan was operating when the hose was being cut, there was still a large plume of smoke around the saw and the employee (Figure B1). Smoke was moving towards the ventilation fan but the rate of generation was much faster than the rate of exhaust, leading to a buildup of smoke around the employee.

- We did not observe it, but it was reported that the facility uses high-efficiency particulate air (HEPA) vacuums and wet cleaning methods when cleaning. It was unclear whether these methods were used in production and nonproduction areas. There were brooms in various areas of the facility, and we were told that employees sometimes dry sweep floors (Figure B2).

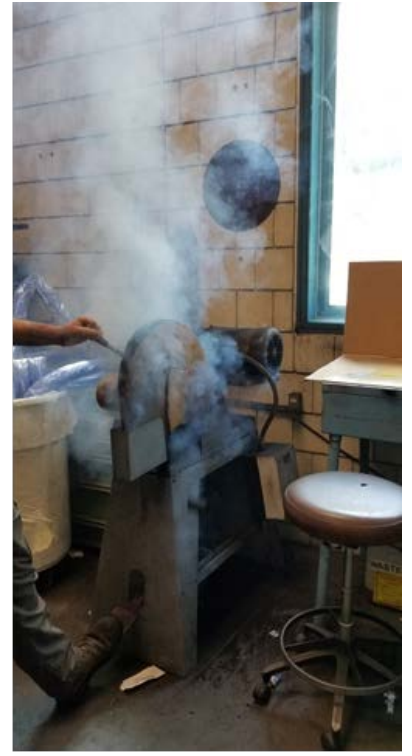

Figure B1. Smoke plume produced from cutting wire-reinforced hose surrounds a worker. There is a ventilation fan in the ceiling that is drawing smoke slowly away. Photo by NIOSH.

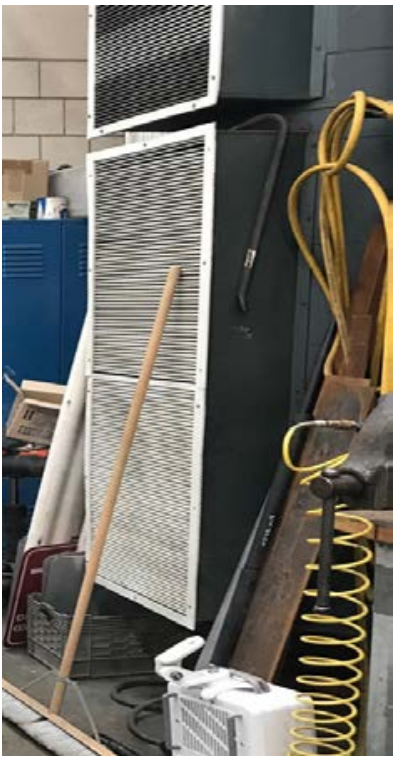

Figure B2. The air intake located in the northwest corner of the boat bay. Photo by NIOSH. 


\section{Methods: Exposure Assessment}

\section{Air Sampling}

We collected two full-shift personal air samples on 10 employees each day, for two days. We collected two full-shift area air samples in three areas of the facility on one day. For each pair of samples,

- We collected and analyzed one sample for a panel of metals using NIOSH Method 7303 [NIOSH 2019].

- We collected and analyzed the second sample for hexavalent chromium using OSHA Method ID-215 (Version 2).

\section{Surface Wipe Sampling}

We collected surface wipe samples from production, break, and office areas in the facility. We also took a surface wipe sample on a desk in an office area located at the top of the stairwell in the northeast corner of the boat bay (Figure A1). This office area is on the second floor and has a door that opens to the top of the stairwell in the boat bay. This doorway is not commonly used by employees who work in the shops but is often utilized by management, safety personnel, and visitors. We used premoistened Ghost Wipes $^{\text {TM }}$ to collect the surface wipe samples, in accordance with NIOSH Method 9100. We used a 100-square-centimeter disposable template to outline the surface area that we sampled. We analyzed the wipe samples for a panel of metals using NIOSH Method 7303 [NIOSH 2019].

\section{Noise Measurements}

We measured full-shift personal noise exposures on 11 employees on our first day of noise sampling and 10 employees on our second day of noise sampling. We also measured area noise levels during three drill tasks.

- We measured personal noise exposures using personal noise dosimeters with the microphone clipped to the employee's collar.

- We measured sound levels at different distances during drill and hammering tasks using a calibrated, battery-operated, type-2 sound level meter.

\section{Results: Exposure Assessment}

\section{Air Sampling}

None of the full-shift personal air sampling results for metals, including hexavalent chromium, were at or above the lowest occupational exposure limits (OELs) (Section C, Table C1). We detected low levels of chromium and hexavalent chromium in eight of the air samples we collected (range: not detected [ND]-0.081 micrograms of chromium per cubic meter of air $\left.\left[\mu \mathrm{g} / \mathrm{m}^{3}\right]\right)$. We detected very low levels of manganese in 16 of the air samples we collected (range: ND-3 $\mu \mathrm{g} / \mathrm{m}^{3}$ ). We detected mostly low levels of nickel in the air samples we collected but found airborne nickel levels approaching the NIOSH recommended exposure limit (REL) in one full-shift personal air sample for nickel (range: ND$\left.13 \mu \mathrm{g} / \mathrm{m}^{3}\right)$. The NIOSH REL for airborne nickel is $15 \mu \mathrm{g} / \mathrm{m}^{3}$.

We found quantifiable concentrations of barium (range: ND-0.38 $\mu \mathrm{g} / \mathrm{m}^{3}$ ), cobalt (range: ND_ $0.55 \mu \mathrm{g} / \mathrm{m}^{3}$ ), lithium (range: ND-0.89 $\mu \mathrm{g} / \mathrm{m}^{3}$ ), titanium (range: ND-0.33 $\mu \mathrm{g} / \mathrm{m}^{3}$ ), zinc (range: ND_ 
$14 \mu \mathrm{g} / \mathrm{m}^{3}$ ), and zirconium (range: ND-0.14 $\mathrm{g} / \mathrm{m}^{3}$ ). There were detectable, but not quantifiable, amounts of antimony, cadmium, calcium, lanthanum, phosphorus, potassium, selenium, silver, strontium, thallium, tin, and vanadium. We did not detect the following elements in our samples: arsenic, beryllium, lead, tellurium, and yttrium.

Concentrations of metals were generally low in the area air samples, and similar to concentrations found in the personal air samples (Table C2). Metals not listed in Table C2 were not detected in the air samples.

\section{Surface Wipe Sampling}

We found aluminum, chromium, copper, iron, magnesium, manganese, and nickel on all break area surfaces that we sampled (Table C3). The highest concentrations were found on the surface of the break table in the ship fitter shop. This table was located near where the ship fitter shop meets the welder shop. There were no walls or barricades separating this table from the production areas. The training room, the break room/office area near the welder shop, and the machinist shop break room were the only break areas that were physically separated from the production areas of the facility. We also found low, but quantifiable concentrations of cadmium, cobalt, lead, lithium, strontium, and yttrium on all break area surfaces sampled. A detectable amount of vanadium was found on the surface of the table in the ship fitter shop.

We found aluminum, chromium, copper, iron, magnesium, manganese, and nickel on all production area surfaces that we sampled (Table C4). We did not detect copper, iron, magnesium, or manganese on the desk in the office at the top of the stairwell adjacent to the boat bay. Aluminum, copper, and iron were the highest concentrations found on production area surfaces. We found low, but quantifiable amounts of cadmium, lead, lithium, and strontium. There were detectable amounts of antimony, cobalt, molybdenum, tellurium, vanadium, and yttrium on production area surfaces.

The minimum detectable concentrations for analytes we sampled for can be found in Table C5. There are no OELs for surface contamination.

\section{Noise Measurements}

For one welder and one pipe fitter, personal noise exposures were above the NIOSH REL for noise of 85 decibels, A-weighted (dBA) (Table C6). All employees were below the OSHA action level (AL) (85 dBA) and the OSHA permissible exposure limit (PEL) (90 dBA) for noise.

We made three area sound measurements while work was being performed on the 49-foot boat. The sound levels measured were

- $83.5 \mathrm{dBA}$ at about 15 feet away from the drill being used on the surface of the boat.

- $\quad 83.4 \mathrm{dBA}$ at about 10 feet away from the drill being used on the surface of the boat.

- $80 \mathrm{dBA}$ at about 10 feet away from the hull with the drill being used below deck.

\section{Methods: Ventilation Assessment}

We evaluated the local exhaust ventilation in the welder, pipe fitter, and carpenter/boat builder shops. We also evaluated the ventilation air intakes in the corners of the boat bay (Figure B2). To approximate 
exhaust airflows, we used an anemometer to take velocity measurements around the openings of the

local exhaust associated with each piece of equipment. We used ventilation smoke to visualize airflow.

\section{Results: Ventilation Assessment}

- We observed many 90-degree turns in the local exhaust ventilation systems. Sharp turns in duct work slow airflow.

- We saw sections of flexible duct connected to nonmobile machines. Flexible duct slows airflow.

- We found no written protocol outlining maintenance and monitoring responsibilities for the local exhaust ventilation systems in the various shops. Employees and management reported some confusion about who was responsible for replacing filters and managing maintenance needs.

- We noticed "dead legs" where duct work lacked connections to machines in the welder and carpenter/boat builder shops.

- We found some tools in the carpenter/boat builder shop not hooked up to the ventilation system. In particular, the large belt sander was not hooked up and has the potential to release large clouds of wood dust.

- We were able to measure a variety of air velocities and visualize airflow (smoke behaviors) for six machines in the carpenter/boat builder shop (Table C7). The local exhaust ventilation system for some machines (e.g., the belt sander) seemed to perform well with very good smoke capture. Other machines (e.g., the drum sander) did not capture smoke well. We were not able to measure air velocities for the disc sander or the band saw. The disc sander was not attached to the ventilation system, while the band saw appeared to be attached with the damper open. However, the exhaust must have been disconnected somewhere in the system because we were unable to measure air velocity.

- We were told that the welder shop local exhaust ventilation system pulls air through a threestage filter arrangement before the air is exhausted into the boat bay. The first stage contains a mesh prefilter. The second stage is a HEPA filter. The third stage contains a Minimum Efficiency Reporting Value (MERV) 15 bag filter.

- We saw hoods in the pipe fitter shop that were tied in place over the working surface (Figure B3). These hoods are only effective when they are placed near emissions sources. 


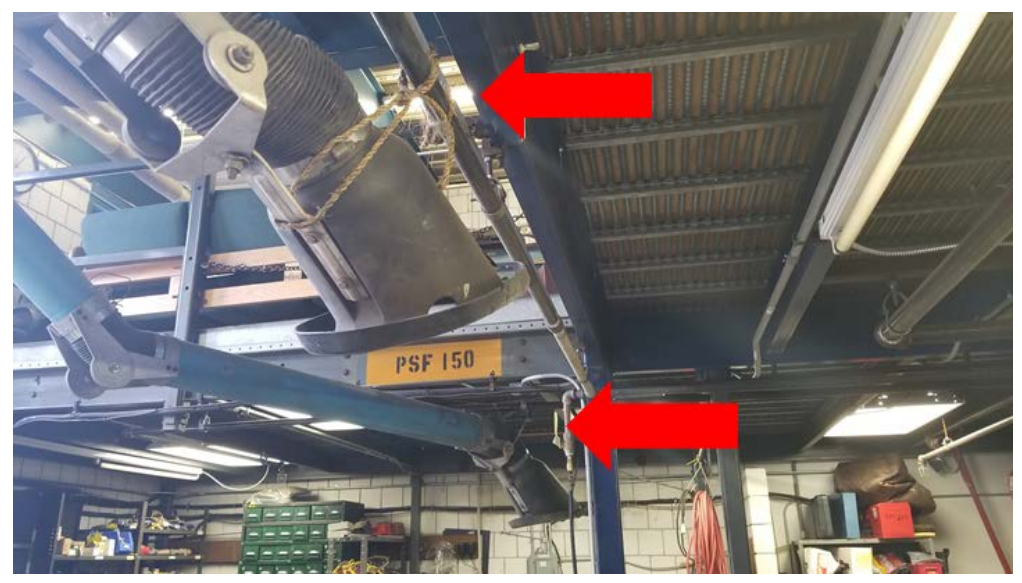

Figure B3. The hoods for the local exhaust ventilation system in the pipe fitter shop had been tied to pipes over workstations using ropes. Photo by NIOSH.

- We observed ventilation air intakes in the northeast and northwest corners of the boat bay. These intakes drew air through air handling units on the rooftop. The air handling units draw the air through an electrostatic filter and then through a MERV 8 filter bank. We were told that the electrostatic filter was cleaned "every so often" but that it had been out of service for about two to three years. The purpose of this system is to circulate air and supply heat to the boat bay. The face velocity was about 250 feet per minute for both intake locations. The ventilation smoke revealed that the intake in the northwest corner was only effective at moving smoke within three feet. Farther away from the intake, smoke hung in the air and slowly dispersed in multiple directions. We were unable to visualize air movement around the northeast intake because it was very close to the open boat bay door. Close to the face of the intake, smoke was rapidly sucked into the system. As we moved closer to the boat bay door, any effect of the air intake was overpowered by the air movement into the boat bay through the open bay door.

\section{Methods: Employee Health Assessment and Biomonitoring}

\section{Confidential Medical Interviews}

During our first visit in February 2018, we invited all employees from the welder, ship fitter, marine mechanic, pipe fitter, and carpenter/boat builder shops to participate in confidential medical interviews. Interviews covered basic demographics, work practices and conditions, and work-related health effects.

\section{Written Questionnaires}

We used the results of the interviews to design the written questionnaire that we administered on our return visit in July 2018. We invited all employees from the welder, ship fitter, machinist, marine mechanic, pipe fitter, electrician, and carpenter/boat builder shops to complete a written questionnaire. Employees from the machinist and electrician shops were included in all parts of the evaluation we performed during our second visit after we learned that they had many of the same exposures as employees of the other shops included in our first visit evaluation. Questionnaires covered basic demographics, work history and practices, training history, work-related health effects, and social history. 


\section{Nasal Examinations}

During the July 2018 visit, we invited employees from the welder, ship fitter, machinist, marine mechanic, pipe fitter, electrician, and carpenter/boat builder shops to participate in nasal examinations. The nasal examinations were performed by a NIOSH physician who evaluated the inside of employees' noses for evidence of irritation, open sores, scars, or perforations that could be related to nickel or chromium exposure.

\section{Urine Nickel, Chromium, and Manganese Testing}

During the July 2018 visit, we invited employees from the welder, ship fitter, machinist, marine mechanic, pipe fitter, electrician, and carpenter/boat builder shops to participate in urine testing for nickel, chromium, and manganese. Urine testing was performed as another method to assess metal exposures among employees. Those participating provided a spot urine specimen at the end of their work shift at the end of their workweek. Urine was analyzed using a standard inductively coupled plasma mass spectrometry method by a laboratory contracted by NIOSH to perform the analysis. The laboratory that analyzed the urine specimens had a reporting limit, similar to a detection limit, for urine concentrations for nickel of 4.0 micrograms per liter $(\mu \mathrm{g} / \mathrm{L})$, for chromium of $1.0 \mu \mathrm{g} / \mathrm{L}$, and for manganese of $2.0 \mu \mathrm{g} / \mathrm{L}$. Urine concentrations of nickel, chromium, and manganese below the respective reporting limit were reported as "none detected."

Urine nickel concentrations were compared to the normal general population concentration for urine nickel of $<4 \mu \mathrm{g} / \mathrm{L}$ and the Finnish Institute of Occupational Health Biomonitoring Action Limit for nickel and slightly soluble nickel salts of $5.9 \mu \mathrm{g} / \mathrm{L}$ (0.1 micromoles per liter), an OEL based on an end of shift, end of workweek urine specimen [Finnish Institute of Occupational Health 2017; WHO 1996]. Elevated urine nickel concentration was defined as an employee of the facility with an end of shift, end of workweek spot urine nickel concentration of $\geq 4 \mu \mathrm{g} / \mathrm{L}$.

Urine chromium concentrations were compared to the normal general population range for urine chromium of $0.22-1.8 \mu \mathrm{g} / \mathrm{L}$ and the ACGIH Biological Exposure Index (BEI $\left.{ }^{\circledR}\right)$ for chromium of $25 \mu \mathrm{g} / \mathrm{L}$ [ACGIH 2019; ATSDR 2012a]. Elevated urine chromium concentration was defined as an employee of the facility with an end of shift, end of workweek spot urine chromium concentration $\geq 25 \mu \mathrm{g} / \mathrm{L}$.

Urine manganese concentrations were compared to the normal general population range for urine manganese of 1-8 $\mu \mathrm{g} / \mathrm{L}$ [ATSDR 2012b]. Elevated urine manganese concentration was defined as an employee of the facility with an end of shift, end of workweek spot urine manganese concentration $>8 \mu \mathrm{g} / \mathrm{L}$.

\section{Results: Employee Health Assessment and Biomonitoring}

\section{Confidential Medical Interviews}

During our first visit, 19 of 21 employees participated in confidential medical interviews. We asked employees if they had any symptoms over the past three months that they thought were related to working at the facility. Six employees reported symptoms that included respiratory symptoms (including cough, shortness of breath, sinusitis, and sneezing, $n=4)$, tinnitus or hearing loss $(n=2)$, and skin irritation $(n=1)$. Two additional employees reported worsening of their chronic eczema or atopic 
dermatitis at work. Among these eight employees reporting possible work-related symptoms or worsening of chronic skin conditions, six spent most of their time at work in the boat bay. Interviewed employees reported that multiple and different job tasks were performed in the boat bay at the same time. These employees also reported limited communication about the job tasks being performed near them while working in the boat bay. As a result, these employees reported that donning the appropriate PPE to prevent or reduce exposures was challenging at times.

When asked about PPE use, 10 employees reported that when they used hearing protection, they used it for grinding $(n=2)$ or "as needed" ( $n=8)$. Nine employees did not specify when they used hearing protection at work. The eight employees who reported using hearing protection "as needed" did not specify how they determined when hearing protection was necessary.

Employees reported using different types of respirators for different tasks at work. Among those who reported using half-mask elastomeric respirators, tasks performed while wearing this type of respirator included insulation work, removal of epoxy decking, grinding, brazing, pipe cutting, spray painting, and any work done below deck on a boat. Employees also reported sometimes using full facepiece elastomeric respirators and filtering facepiece respirators but did not specify the tasks for which they typically used these types of respirators.

Some employees expressed concern about inadequate supplies of disposable PPE and replacement filters for equipment at times. When supplies of PPE were lacking, employees reported searching the supplies of other shops to find what they needed until reordering could occur for their shop. Other health and safety concerns reported by employees during the interviews included a lack of adequate health and safety training; poor air quality in the facility and while working below deck inside a boat; inadequate equipment and facility maintenance; overexposure to noise; and inconsistencies in the medical surveillance program.

\section{Written Questionnaires}

During our second visit, 19 of 20 employees completed a written questionnaire. Table C8 shows the tasks these employees reported that they performed. The most common tasks were grinding, metal cutting, and needle gunning. Table C9 shows the facility location where the most time was spent at work by employees who completed a questionnaire. Twelve $(63.2 \%)$ employees reported spending most of their time working in the boat bay.

Table C10 shows the frequency of hygiene practices by responding employees. A few employees reported inconsistently washing their hands before eating, drinking, smoking, and/or leaving work. Nine employees reported sometimes or always eating or drinking or storing food and/or drinks in their work area.

All 19 employees reported participating in cleaning. Of these, 17 reported cleaning the facility daily or weekly. Fourteen reported dry sweeping facility floors and eight reported wiping surfaces with a dry cloth, processes that can suspend dust and other contaminants in the air. Among the 19 employees who reported vacuuming the facility, 16 reported using a vacuum equipped with a HEPA filter.

During our first visit, seven employees reported that safety training was inadequate. On our second visit questionnaires, we asked employees if they had received training in six work-related safety and health 
topics. Table C11 shows the training employees reported receiving in the past year. Although most employees reported receiving training in these topics in the past year, several employees noted that this training was only very recently updated between our first and second visits. Prior to this recent training update, they reported that they did not have training in these work-related safety and health topics for several years or longer.

All 19 responding employees reported using hearing protection at work, although only for a median use of 2 hours per day (range: 30 minutes-10 hours per day). Of the 18 employees who used eye protection at work, the median time of use was 8 hours per day (range: 4-12 hours per day). Respiratory protection was only infrequently used among the 14 employees who reported wearing respirators at work, with a median time worn of one hour per day (range: 5 hours per month-3 hours per day).

We asked employees about symptoms and health effects that could be related to exposures at the facility. Table C12 shows symptoms and health effects experienced at work over the past 3 months by responding employees. Among nine employees with reported tinnitus, four reported that it occurred daily, and six reported trouble hearing clearly or fully. Three additional employees without tinnitus reported trouble hearing clearly. Three of the nine employees with trouble hearing clearly reported that the hearing trouble began after starting work at the facility.

The median time spent wearing hearing protection among those reporting tinnitus and/or hearing loss was three hours per day (range: 30 minutes-10 hours). Based on medical record review, only 8 of 19 questionnaire respondents had audiometry testing over the period of 1/1/2013-6/6/2018. Nine of 12 employees who reported tinnitus and/or hearing trouble did not have records of audiometry testing. Two of these nine employees reported that their hearing trouble began after starting work at the facility, and one was not sure when the hearing trouble began. Among the three employees reporting tinnitus and/or hearing trouble who did have record of audiometry testing, one had normal results and two had evidence of mild to moderate hearing loss on their most recent test. Neither of the two employees with hearing loss on their most recent audiometry testing had evidence of audiometry testing within 24 months of the date we received the records.

Seven employees reported a history of dermatitis at work during the past three months. Six of these employees noted dermatitis of the upper extremities, with involvement of arms, wrists, and/or hands. Among those with a history of dermatitis at work in the past three months, all reported participating in cleaning activities and working with multiple, different chemicals or solvents. None reported always wearing nitrile gloves while cleaning, and only one reported always wearing nitrile gloves when handling chemicals or solvents at work. Five reported sometimes wearing nitrile gloves while cleaning, and six reported sometimes wearing nitrile gloves when using chemicals or solvents at work. Five employees reported improvement of the dermatitis when they are away from work. One employee reported a healthcare provider diagnosis of a possible allergic reaction to nickel-copper piping as the source for the dermatitis.

We also asked about respiratory symptoms experienced at work over the past three months (Table C12). Nine employees reported at least one respiratory symptom at work during the past three months. Symptoms and health effects reported by at least one employee included shortness of breath, chronic cough, sinus infections, wheezing, nasal irritation, and nose bleeds. Nasal irritation and chronic 
cough were the most common respiratory symptoms reported. One employee reported worsening of chronic respiratory and allergy conditions at work. Among those reporting respiratory symptoms at work over the past three months, seven spent most of their time at work in the boat bay.

\section{Nasal Examinations}

We looked inside 19 employees' noses for evidence of irritation, open sores, scars, or perforations (open holes through the nasal septum, the cartilage that divides the two nostrils). All employees evaluated had intact nasal septa without evidence of perforation or open sores. However, 13 employees had evidence of irritation of the membranes inside the nose.

Among those with nasal membrane irritation, 8 reported spending most of their time at work in the boat bay, and 11 reported participating in grinding at work. All seven employees who reported a history of cigarette smoking and/or e-cigarette use had evidence of nasal membrane irritation.

\section{Urine Nickel, Chromium, and Manganese Testing}

Among the 20 employees, 15 participated in end of shift, end of workweek urine testing for nickel, chromium, and manganese. Urine nickel results ranged from none detected to $13 \mu \mathrm{g} / \mathrm{L}$. One employee's result, $13 \mu \mathrm{g} / \mathrm{L}$, was above the Finnish Institute of Occupational Health Biomonitoring Action Limit for nickel and slightly soluble nickel salts of $5.9 \mu \mathrm{g} / \mathrm{L}$ [Finnish Institute of Occupational Health 2017]. Two of the results, $4.6 \mu \mathrm{g} / \mathrm{L}$ and $13 \mu \mathrm{g} / \mathrm{L}$, were above the normal general population level of nickel in the urine of $<4 \mu \mathrm{g} / \mathrm{L}$ [WHO 1996].

The two employees with elevated urine nickel levels reported spending most of their time at work in the boat bay, routinely soldering and brazing copper-nickel pipe, and taking part in cleaning activities, including dry sweeping. Additional reported work practices included never wearing nitrile gloves while cleaning; eating, drinking, or storing food or drinks in work areas; inconsistent handwashing before eating, drinking, or smoking at work; and smoking. One employee reported a history of dermatitis and multiple respiratory symptoms at work in the three months prior to our second visit that improved away from work. Both had evidence of nasal membrane irritation on nasal examination.

None of the employees tested had detectable concentrations of chromium in their urine. All of the results were below the BEI limit of $25 \mu \mathrm{g} / \mathrm{L}$ and within the range expected in persons in the general population [ACGIH 2019; ATSDR 2012a]. None of the employees tested had detectable concentrations of manganese in their urine. All of the results were within the range expected in persons in the general population [ATSDR 2012b].

\section{Discussion}

Other than recommendations from the 2015 welding assessment for hearing protection during grinding and welding activities, specific written plans for hearing protection requirements, such as activities requiring hearing protection or types of hearing protection required, were not available. If written plans for hearing protection requirements were in place, it did not appear that most employees were aware of these plans, because only two interviewed employees reported consistently using hearing protection for a specific activity (i.e., grinding). Most interviewed employees either did not report when they used hearing protection or reported using it "as needed." In addition, questionnaire respondents reported using hearing protection for a median of only 2 hours each day (range: 30 minutes-10 hours). 
Some employees pointed out an ear plug dispenser mounted on the wall. The dispenser was clear plastic and appeared to be full of ear plugs. Upon closer inspection, the ear plugs seen through the plastic were stuck to the inside of the dispenser and not able to fall out of the bottom. It was unclear exactly why the ear plugs were stuck to the dispenser, but it was possibly due to static cling. Employees reported that they often noticed that they could see what appeared to be a full dispenser but were unable to easily access the hearing protection.

Although we were told that the work level in the facility during our second visit was less than typical, two employees were exposed to noise levels above the NIOSH REL for noise. While our area noise measurements during drill saw activity were below OELs, we measured 10-15 feet away from the noise source. The noise at the source was likely substantially higher than our measurements and could exceed OELs. Because the work performed during our second visit was less than normal, including one day with no work performed, it is likely that on days when more work activities are performed, noise exposure levels could be higher.

Questionnaire responses and review of medical records also suggest that employees may be overexposed to noise while working at the facility. Among 19 questionnaire respondents, 12 reported tinnitus and/or trouble hearing clearly. Although audiometry results were only available for 3 of these 12 employees, 2 of these 3 had evidence of mild to moderate hearing loss on their most recent audiometry testing. One of these employees had only one audiometry record available, preventing us from evaluating for evidence of an STS. The other did not have evidence of an STS on the audiometry records we reviewed, but neither employee had audiometry records within 24 months of the date we received the records.

Audiometry testing records were not available for nine employees who reported tinnitus and/or trouble hearing clearly. In addition, four questionnaire respondents who denied having tinnitus or trouble hearing clearly had evidence of hearing loss on audiometry testing. The audiometry results for two of these four employees demonstrated findings suggestive of an STS. However, we did not have enough information from the records provided to confirm whether these results satisfied OSHA or NIOSH STS criteria. Finally, as noted previously, a physician determined that one employee's hearing loss was the result of exposure to noise at the facility.

Tinnitus has been associated with work-related noise exposures [Steinmetz et al. 2009] and objectively measured hearing loss, with hearing loss detected in $85 \%-96 \%$ of those with tinnitus in some studies [Martines et al. 2010; Savastano 2008]. Study results evaluating the association between subjectively reported hearing loss and the presence of objective hearing loss on audiometry are mixed. A recent study from Brazil found that subjective measures of hearing loss correlated with audiometry findings [Costa-Guarisco et al. 2017]. However, another analysis of a nationally representative sample in the United States found that demographic factors, such as age, race, and education level, may impact the accuracy of subjective measures of hearing loss [Kamil et al. 2015].

Our small sample size in this report and the lack of available and up-to-date audiometry testing records prevented us from evaluating for statistical associations between hearing-related symptoms reported on questionnaires and objective findings on audiometry. However, the results of our evaluation and evidence from the scientific literature demonstrate the importance of ensuring consistent adherence to 
the facility's written hearing conservation program, including employee training, periodic noise monitoring, annual audiometry testing, implementation of controls to reduce employee noise exposures, and establishment of clear written guidance for hearing protection.

Despite relatively low air exposures to metals during our sampling, 2 of the 15 employees participating in end of shift, end of workweek urine metal testing had urine nickel concentrations that were elevated above the normal general population urinary nickel level. One of these urine nickel concentrations was elevated above the Finnish Institute of Occupational Health Biomonitoring Action Limit for nickel and slightly soluble nickel salts [Finnish Institute of Occupational Health 2017]. In addition, one employee had a full-shift personal airborne nickel concentration of $13 \mu \mathrm{g} / \mathrm{m}^{3}$, which is close to the current NIOSH REL for nickel of $15 \mu \mathrm{g} / \mathrm{m}^{3}$.

Evidence suggests that increased urinary nickel levels may be associated with work and personal hygiene practices [ATSDR 2005; Sunderman et al. 1986]. Our small sample size did not allow us to make statistical associations between elevated urine nickel concentrations and specific factors. However, work practices reported on questionnaires, such as working with copper-nickel pipe, and cleaning activities, such as dry sweeping, a practice that suspends contaminants in the air, may have contributed to inhalational exposure to nickel. Personal practices identified on questionnaires and workplace observations, such as eating, drinking, or storing food or drinks in work areas; inconsistent handwashing before eating, drinking, or smoking at work; and smoking, may have also resulted in unintentional ingestion or inhalation of nickel.

We detected the presence of nickel on all production, office, and break area surfaces we sampled further suggesting that eating, drinking, or storing food or drinks in these areas could result in unintentional ingestion. Although the scientific literature suggests that urinary nickel excretion among nickel-exposed workers increases over the course of a work shift and throughout the workweek [ATSDR 2005], studies also indicate that elevated urine nickel levels may persist even after nickel exposures are reduced or eliminated [Boysen et al. 1984; Sunderman et al. 1986]. Because the amount of work done at the facility during our second visit was less than typical, the urine nickel concentrations we found may represent declining levels from exposures that occurred prior to our visit. If so, our results could significantly underestimate typical nickel exposures at the facility.

Although we detected air concentrations of hexavalent chromium well below established OELs, we found levels above the minimum detectable concentration in eight of the air samples. None of the 15 employees who participated in end of shift, end of workweek urine chromium testing had detectable levels of chromium in their urine. Among the 19 employees who participated in nasal examinations, 13 had evidence of nasal membrane irritation. Although both nickel and chromium exposure can irritate the nasal membranes, this finding is nonspecific because other factors, such as dust exposure or environmental allergens, can cause similar findings. We did not find evidence of more severe complications of hexavalent chromium exposure like scarring or nasal septal perforations during nasal examinations.

According to facility management, employees of the welder, ship fitter, and pipe fitter shops were included in the chromium medical surveillance program. Enrollment was based on how frequently employees in these shops work with chromium compounds and the wide variation in the type of work 
these shops perform with these substances. Based on our review of the written chromium medical surveillance program and medical records from the clinic that performs all medical surveillance evaluations for facility employees, it did not appear that welders, ship fitters, or pipe fitters at the facility received chromium medical surveillance evaluations over the period of $1 / 1 / 2013-6 / 6 / 2018$. If these employees are enrolled in the facility's chromium medical surveillance program, they should begin receiving all components of the chromium medical surveillance evaluation specified in the program. Records of these evaluations should be maintained according to clinic policies for handling other medical records.

Our air sampling detected low levels of the major components of the main types of metals that are welded in the facility. A 2017 report we reviewed did not detect any metals in the air. The 2017 report noted that the welding work and grinding work were "typical." It is not surprising that the 2017 survey did not detect contaminants given that the samples were area samples and not personal samples. It is preferable to collect personal samples to estimate exposures. Area samples are not necessarily representative of personal exposures.

Detecting these low levels of contaminants during our visit was not surprising given the lesser amount of work that was being done. We also found quantifiable concentrations of metals on surfaces in nonproduction areas. This could be because some break areas are not separate from production areas, which could allow contamination to easily migrate from production to nonproduction areas. As noted earlier, surface contamination may have contributed to nickel exposures among the two employees with urine nickel concentrations that were elevated above general population levels.

We identified several issues related to communication at the facility during our evaluation. Employees reported a lack of communication between shops at times when different work activities were being performed at the same time in the boat bay. Because exposures may vary significantly by job task, employees expressed concern that this lack of communication kept them from taking necessary actions, such as donning proper PPE, to prevent or reduce their exposures.

Employees also reported a perceived lack of response and acknowledgement of concerns on health and safety matters from management representatives. For example, we found uncertainty among employees and management as to when the local exhaust ventilation system filters were last changed, and who was responsible for that task and other maintenance activities. Through workplace investigations, NIOSH investigators have found that reduced job satisfaction and poor communication are common where air quality complaints occur. These issues may be related to personnel organizational factors, conflict among personnel, or lack of job security. Providing feedback, involving employees in decision making, and allowing employees to provide input to the employer are associated with greater job satisfaction and positive perceptions of work [Kain and Jex 2010]. Furthermore, an individual's health can be affected by a perceived lack of response to odorous chemical exposure related to air quality, especially if the individual believes that the exposure is hazardous and has negative attitudes toward the exposure [Claeson et al. 2013]. 


\section{Limitations}

This evaluation is subject to several limitations. First, industrial hygiene sampling can only document exposures on the days of sampling in the locations sampled. These results may not be representative of conditions during other days. Second, employees told us that the amount of work performed in the facility during the days we sampled was less than typically expected during this time of year. Third, the small size and homogenous nature of the population sampled limit the generalizability of our evaluation results. Finally, because our interviews and questionnaires asked employees about the past, the results are subject to recall bias.

\section{Conclusions}

Although the amount of work performed during our second visit was less than typically expected, results of our document review, noise sampling, and questionnaires suggest that employees of the facility are overexposed to noise. Improving adherence to the facility's hearing conservation program is needed to reduce employees' noise exposures. Based on the biological monitoring results, some employees may be overexposed to nickel. Improving work practices and changing personal practices can reduce potential exposure. Finally, we identified areas where communication needs improvement. Regular meetings of the facility's health and safety committee will help keep safety plans current and improve communication between employees and management about safety-related issues. 


\section{Section C: Tables}

Table C1. Full-shift personal air sample results for selected metals $\left(\mu \mathrm{g} / \mathrm{m}^{3}\right)$

\begin{tabular}{|c|c|c|c|c|c|c|}
\hline Day & Job title & $\begin{array}{c}\text { Time } \\
\text { (minutes) }\end{array}$ & Aluminum & Chromium & $\begin{array}{l}\text { Hexavalent } \\
\text { chromium* }\end{array}$ & Copper \\
\hline \multirow[t]{10}{*}{1} & Marine mechanic 1 & 523 & {$[1.6]$} & ND & - & 0.31 \\
\hline & Marine mechanic 2 & 514 & [1] & 0.69 & - & 0.96 \\
\hline & Marine mechanic 3 & 365 & ND & ND & - & ND \\
\hline & Pipe fitter 1 & 524 & [2.4] & ND & - & 0.52 \\
\hline & Pipe fitter 2 & 521 & 10 & 0.5 & - & 8.9 \\
\hline & Pipe fitter 3 & 524 & 3.2 & [0.15] & - & 1.3 \\
\hline & Pipe fitter 4 & 469 & 3.5 & ND & - & 1.4 \\
\hline & Welder 1 & 306 & [5] & {$[0.28]$} & - & 1.8 \\
\hline & Welder 2 & 457 & [1.3] & {$[0.22]$} & - & {$[0.17]$} \\
\hline & Ship fitter 1 & 371 & 6.3 & ND & - & [0.18] \\
\hline \multirow[t]{10}{*}{2} & Marine mechanic 2 & 507 & ND & [0.11] & 0.0053 & [0.23] \\
\hline & Marine mechanic 3 & 381 & ND & ND & ND & {$[0.17]$} \\
\hline & Pipe fitter 1 & 533 & ND & ND & [0.0013] & {$[0.17]$} \\
\hline & Pipe fitter 2 & 517 & 8 & [0.43] & 0.071 & 0.57 \\
\hline & Pipe fitter 3 & $86 / 512 \dagger$ & ND & ND & 0.02 & ND \\
\hline & Pipe fitter 4 & 490 & ND & ND & [0.0012] & 1.3 \\
\hline & Welder 1 & 438 & 6.7 & [0.29] & 0.019 & 0.81 \\
\hline & Welder 2 & 453 & 9.2 & [0.13] & 0.081 & {$[0.25]$} \\
\hline & Ship fitter 1 & 245 & {$[6.2]$} & {$[0.3]$} & 0.011 & [0.24] \\
\hline & Machinist 1 & 423 & 4.1 & 23 & 0.021 & 6.6 \\
\hline \multicolumn{3}{|c|}{ NIOSH REL } & $10,000 / 5,000 \ddagger$ & 500 & 0.2 & 1,000 \\
\hline \multicolumn{3}{|c|}{ OSHA PEL } & $15,000 / 5,000 \ddagger$ & 1,000 & 5 & 1,000 \\
\hline \multicolumn{3}{|c|}{ ACGIH TLV } & $1,000 \S$ & 500 & 0.2 & 1,000 \\
\hline \multicolumn{3}{|c|}{ Minimum detectable concentration } & 5 & 0.6 & 3 & 0.5 \\
\hline \multicolumn{3}{|c|}{ Minimum quantifiable concentration } & 18 & 2.8 & 0.0081 & 1.7 \\
\hline
\end{tabular}

[ ] = Estimated concentration; this concentration was between the minimum detectable and minimum quantifiable concentrations.

*Hexavalent chromium was only sampled for on day two.

†The time is for the metals and hexavalent chromium samples. Employee did not wear the metals sampling pump for full shift.

$\ddagger$ Total/respirable aluminum

§Respirable fraction

IThese values varied slightly from sample to sample and day to day. The most conservative numbers are listed here. 
Table C1, continued. Full-shift personal air sample results for selected metals $\left(\mu \mathrm{g} / \mathrm{m}^{3}\right)$

\begin{tabular}{cccccccc}
\hline Day & Job title & $\begin{array}{c}\text { Time } \\
\text { (minutes) }\end{array}$ & Iron & Magnesium & Manganese & Molybdenum & Nickel \\
\hline 1 & Marine mechanic 1 & 523 & 8 & ND & 0.13 & ND & {$[0.044]$} \\
Marine mechanic 2 & 514 & 44 & ND & 0.44 & ND & 0.56 \\
Marine mechanic 3 & 365 & 11 & ND & 0.13 & ND & ND \\
Pipe fitter 1 & 524 & 11 & ND & 0.12 & ND & {$[0.08]$} \\
Pipe fitter 2 & 521 & 365 & {$[4]$} & 3 & {$[0.31]$} & 1.3 \\
Pipe fitter 3 & 524 & 4.3 & ND & 0.071 & ND & 0.41 \\
Pipe fitter 4 & 469 & 5.5 & ND & 0.71 & ND & {$[0.084]$} \\
Welder 1 & 306 & 53 & ND & 1.1 & ND & {$[0.18]$} \\
Welder 2 & 457 & 3.5 & ND & 0.085 & ND & ND \\
Ship fitter 1 & 371 & 3.6 & ND & 0.08 & ND & ND \\
\hline Marine mechanic 2 & 507 & 1.9 & ND & {$[0.022]$} & ND & ND \\
Marine mechanic 3 & 381 & 13 & ND & 0.15 & ND & ND \\
Pipe fitter 1 & 533 & {$[1.1]$} & ND & ND & ND & ND \\
Pipe fitter 2 & 517 & 14 & ND & 0.15 & {$[0.19]$} & 0.28 \\
Pipe fitter 3 & 512 & ND & ND & ND & ND & ND \\
Pipe fitter 4 & 490 & 1.7 & ND & ND & ND & ND \\
Welder 1 & 438 & 25 & ND & 0.63 & ND & {$[0.089]$} \\
Welder 2 & 453 & 6.8 & ND & 0.17 & ND & {$[0.12]$} \\
Ship fitter 1 & 245 & 5.2 & ND & {$[0.069]$} & ND & ND \\
Machinist 1 & 423 & 110 & ND & 1.8 & 2.8 & 13 \\
\hline OSHA PEL & & $5,000^{*}$ & - & 1,000 & - & 15 \\
Minimum detectable concentration & & $10,000^{*}$ & $15,000 \dagger$ & 5,000 & 5,000 & 1,000 \\
\hline Minimum quantifiable concentration & $5,000^{*}$ & $10,000 \dagger$ & $100 / 20 \ddagger$ & $500 \S$ & 1,500 \\
\hline
\end{tabular}

[ ] = Estimated concentration; this concentration was between the minimum detectable and minimum quantifiable concentrations.

*As iron oxide

†As magnesium oxide

¥The ACGIH TLV for inhalable and respirable manganese.

§Respirable fraction

IThese values varied slightly from sample to sample and day to day. The most conservative numbers are listed here. 
Table C2. Full-shift area air sample results*

\begin{tabular}{lccc}
\hline What we sampled & \multicolumn{2}{c}{ Air concentration, micrograms per cubic meter of air } \\
\cline { 2 - 4 } & Ship fitter table & Deck of aluminum boat & Deck of 49' boat \\
\hline Chromium & {$[0.16]$} & $\mathrm{ND}$ & $\mathrm{ND}$ \\
Cobalt & {$[0.066]$} & $\mathrm{ND}$ & $\mathrm{ND}$ \\
Copper & {$[0.16]$} & $\mathrm{ND}$ & {$[0.12]$} \\
Hexavalent chromium & {$[0.0031]$} & {$[0.0022]$} & 0.0041 \\
Iron & {$[1.5]$} & {$[0.59]$} & {$[1.2]$} \\
Potassium & {$[0.63]$} & {$[0.49]$} & {$[0.82]$} \\
Vanadium & {$[0.34]$} & $\mathrm{ND}$ & $\mathrm{ND}$ \\
\hline
\end{tabular}

[ ] = Estimated concentration; this concentration was between the minimum detectable and minimum quantifiable concentrations.

*The minimum detectable concentrations $\left(\mu \mathrm{g} / \mathrm{m}^{3}\right)$ were 0.1 for chromium, 0.02 for cobalt, 0.1 for copper, and 0.2 for vanadium. The minimum quantifiable concentration $\left(\mu \mathrm{g} / \mathrm{m}^{3}\right)$ was 0.51 for chromium, 0.09 for cobalt, 1.7 for copper, 0.0041 for hexavalent chromium, 1.7 for iron, 1.3 for potassium, and 0.85 for vanadium.

†The sample durations were 482 minutes for the ship fitter table, 484 minutes for the deck of the aluminum boat, and 487 minutes for the deck of the 49 ' boat. 
Table C3. Surface wipe sample results for a panel of metals in break areas (micrograms per 100 square centimeters)*

\begin{tabular}{|c|c|c|c|c|c|c|c|}
\hline Analytes $†$ & $\begin{array}{l}\text { Training } \\
\text { room } \\
\text { refrigerator }\end{array}$ & $\begin{array}{c}\text { Shop } 2 \\
\text { break room } \\
\text { microwave } \\
\text { buttons }\end{array}$ & $\begin{array}{l}\text { Welder } \\
\text { shop } \\
\text { locker }\end{array}$ & $\begin{array}{l}\text { Welder } \\
\text { shop } \\
\text { refrigerator }\end{array}$ & $\begin{array}{l}\text { Ship fitter } \\
\text { work/break } \\
\text { table }\end{array}$ & $\begin{array}{l}\text { Pipe fitter } \\
\text { shop } \\
\text { break } \\
\text { table }\end{array}$ & $\begin{array}{l}\text { Pipe fitter } \\
\text { shop } \\
\text { refrigerator }\end{array}$ \\
\hline Aluminum & 21 & 14 & 3.2 & 84 & 2,000 & 7.7 & 85 \\
\hline Barium & 1.1 & 0.64 & {$[0.12]$} & 2.2 & 3.5 & 0.13 & 1.8 \\
\hline Cadmium & [0.043] & {$[0.037]$} & ND & [0.064] & ND & ND & 0.89 \\
\hline Calcium & 170 & 120 & 85 & 120 & 110 & 110 & 190 \\
\hline Chromium & 0.66 & 0.57 & {$[0.17]$} & 2.4 & 11 & 0.26 & 2.8 \\
\hline Cobalt & ND & {$[0.066]$} & ND & {$[0.14]$} & 0.25 & ND & {$[0.19]$} \\
\hline Copper & 15 & {$[4.4]$} & [2.1] & 9.4 & 5.4 & 4.7 & 91 \\
\hline Iron & 36 & 29 & 9.1 & 150 & 180 & 6.5 & 130 \\
\hline Lead & {$[0.66]$} & ND & ND & {$[0.9]$} & ND & ND & 2.6 \\
\hline Lithium & 0.072 & ND & ND & 0.19 & {$[0.037]$} & ND & 0.16 \\
\hline Magnesium & 9.7 & 12 & {$[1.1]$} & 8.5 & 97 & [2.8] & 34 \\
\hline Manganese & 0.71 & 0.43 & {$[0.26]$} & 3.5 & 8.8 & {$[0.16]$} & 2.9 \\
\hline Molybdenum & ND & ND & ND & {$[0.2]$} & 0.55 & ND & 0.54 \\
\hline Nickel & 10 & 0.71 & 1 & 2.4 & 4.8 & 1.4 & 18 \\
\hline Phosphorus & [6.9] & ND & ND & ND & {$[17]$} & ND & {$[17]$} \\
\hline Potassium & 160 & 38 & ND & 97 & 38 & [23] & 240 \\
\hline Silver & 1.7 & ND & ND & ND & ND & ND & 0.66 \\
\hline Strontium & 0.25 & [0.13] & ND & 0.17 & 0.13 & [0.064] & 0.43 \\
\hline Tin & [0.72] & {$[0.86]$} & ND & [0.68] & [0.91] & ND & [0.82] \\
\hline Titanium & 0.3 & [0.12] & [0.041] & 0.97 & 1.4 & ND & 0.49 \\
\hline Vanadium & ND & ND & ND & ND & [0.62] & ND & ND \\
\hline Yttrium & [0.0095] & {$[0.0067]$} & ND & [0.0091] & [0.0091] & ND & {$[0.006]$} \\
\hline Zinc & [11] & ND & ND & [14] & ND & ND & 35 \\
\hline Zirconium & 0.6 & 0.18 & 0.048 & 0.16 & 0.092 & 0.045 & 0.27 \\
\hline
\end{tabular}

[ ] = Estimated concentration; this concentration was between the minimum detectable and minimum quantifiable concentrations.

*Minimum detectable and minimum quantifiable concentrations can be found in Table C5.

tWe did not detect the following metals in any of the samples: antimony, arsenic, beryllium, lanthanum, selenium, tellurium, and thallium. 
Table C4. Surface wipe sample results for a panel of metals in production and office areas (micrograms per 100 square centimeters)*

\begin{tabular}{|c|c|c|c|c|}
\hline Analytes $†$ & $\begin{array}{c}\text { Carpenter/boat } \\
\text { builder workstation }\end{array}$ & Mechanic bench & $\begin{array}{l}\text { Mechanic bench } \\
\text { near HVAC intake }\end{array}$ & $\begin{array}{l}\text { Office desk adjacent } \\
\text { to boat bay }\end{array}$ \\
\hline Aluminum & 110 & 69 & 150 & [1.3] \\
\hline Antimony & [1.1] & ND & [0.83] & ND \\
\hline Barium & 10 & 4.2 & 6.1 & {$[0.075]$} \\
\hline Cadmium & 0.28 & 0.24 & 0.76 & ND \\
\hline Calcium & 400 & 130 & 230 & 89 \\
\hline Chromium & 5.3 & 2.6 & 10 & ND \\
\hline Cobalt & 0.35 & {$[0.1]$} & 0.75 & ND \\
\hline Copper & 72 & 42 & 620 & ND \\
\hline Iron & 510 & 150 & 2,700 & ND \\
\hline Lead & 17 & 3.5 & 36 & ND \\
\hline Lithium & 0.17 & 0.13 & 0.14 & {$[0.021]$} \\
\hline Magnesium & 49 & 7.4 & 35 & ND \\
\hline Manganese & 11 & 2.2 & 17 & ND \\
\hline Molybdenum & {$[0.32]$} & 0.38 & 1.2 & ND \\
\hline Nickel & 5.6 & 2 & 43 & 0.59 \\
\hline Phosphorus & [12] & 20 & 170 & ND \\
\hline Potassium & 81 & [19] & 60 & [11] \\
\hline Silver & {$[0.031]$} & [0.033] & 12 & [0.054] \\
\hline Strontium & 1.5 & 0.49 & 0.92 & ND \\
\hline Tellurium & ND & ND & [1.3] & ND \\
\hline Tin & 2.9 & [0.97] & 15 & ND \\
\hline Titanium & 2.6 & 0.42 & 2.1 & ND \\
\hline Vanadium & [0.33] & ND & [0.67] & ND \\
\hline Yttrium & 0.069 & [0.0063] & 0.047 & [0.0049] \\
\hline Zinc & 200 & 100 & 190 & ND \\
\hline Zirconium & 0.34 & 0.069 & 0.13 & 0.044 \\
\hline
\end{tabular}

[ ] = Estimated concentration; this concentration was between the minimum detectable and minimum quantifiable concentrations.

*Minimum detectable and minimum quantifiable concentrations can be found in Table C5.

tWe did not detect the following metals in any of these samples: arsenic, beryllium, lanthanum, selenium, and thallium. 
Table C5. Minimum detectable and minimum quantifiable concentrations for surface wipe samples for the panel of metals (micrograms per cubic meter of air)

\begin{tabular}{|c|c|c|}
\hline Analytes & Minimum detectable concentration & Minimum quantifiable concentration \\
\hline Aluminum & 0.6 & 2 \\
\hline Antimony & 0.8 & 2.6 \\
\hline Arsenic & 1 & 3.9 \\
\hline Barium & 0.04 & 0.12 \\
\hline Beryllium & 0.01 & 0.034 \\
\hline Cadmium & 0.03 & 0.11 \\
\hline Calcium & 2 & 6.2 \\
\hline Chromium & 0.07 & 0.23 \\
\hline Cobalt & 0.06 & 0.21 \\
\hline Copper & 1 & 4.5 \\
\hline Iron & 2 & 6.5 \\
\hline Lanthanum & 0.03 & 0.099 \\
\hline Lead & 0.5 & 1.6 \\
\hline Lithium & 0.02 & 0.054 \\
\hline Magnesium & 1 & 4 \\
\hline Manganese & 0.09 & 0.32 \\
\hline Molybdenum & 0.1 & 0.38 \\
\hline Nickel & 0.1 & 0.46 \\
\hline Phosphorus & 6 & 19 \\
\hline Potassium & 9 & 28 \\
\hline Selenium & 3 & 8.6 \\
\hline Silver & 0.03 & 0.1 \\
\hline Strontium & 0.04 & 0.13 \\
\hline Tellurium & 1 & 3.7 \\
\hline Thallium & 0.7 & 2.3 \\
\hline Tin & 0.4 & 1.2 \\
\hline Titanium & 0.04 & 0.15 \\
\hline Vanadium & 0.3 & 1 \\
\hline Yttrium & 0.003 & 0.012 \\
\hline Zinc & 8 & 26 \\
\hline Zirconium & 0.01 & 0.037 \\
\hline
\end{tabular}

C-6 
Table C6. Full-shift noise measurement results in decibels, A-weighted (dBA)

\begin{tabular}{|c|c|c|c|}
\hline Job title & $\begin{array}{l}\text { Result using NIOSH } \\
\text { REL criterion* }\end{array}$ & $\begin{array}{l}\text { Result using OSHA } \\
\text { action level criterion* }\end{array}$ & $\begin{array}{l}\text { Result using OSHA } \\
\text { PEL criterion† }\end{array}$ \\
\hline \multicolumn{4}{|l|}{ Day 1} \\
\hline Marine mechanic 1 & 82 & 74 & 69 \\
\hline Marine mechanic 2 & 80 & 73 & 66 \\
\hline Marine mechanic 3 & 72 & 62 & 47 \\
\hline Pipe fitter 1 & 91 & 82 & 81 \\
\hline Pipe fitter 2 & 82 & 73 & 70 \\
\hline Pipe fitter 3 & 81 & 71 & 64 \\
\hline Pipe fitter 4 & 78 & 69 & 62 \\
\hline Welder 1 & 79 & 73 & 62 \\
\hline Welder 2 & 68 & 53 & 48 \\
\hline Welder 3 & 81 & 70 & 66 \\
\hline Ship fitter 1 & 78 & 71 & 63 \\
\hline \multicolumn{4}{|l|}{ Day 2} \\
\hline Marine mechanic 1 & 81 & 72 & 68 \\
\hline Marine mechanic 3 & 76 & 68 & 55 \\
\hline Pipe fitter 1 & 79 & 70 & 63 \\
\hline Pipe fitter 2 & 81 & 72 & 66 \\
\hline Pipe fitter 3 & 78 & 67 & 64 \\
\hline Pipe fitter 4 & 79 & 72 & 64 \\
\hline Welder 1 & 88 & 82 & 71 \\
\hline Welder 3 & 74 & 63 & 53 \\
\hline Ship fitter 1 & 74 & 64 & 54 \\
\hline Machinist 1 & 78 & 71 & 60 \\
\hline $\begin{array}{l}\text { Noise exposure limits } \\
\text { (8-hour time-weighted averages) }\end{array}$ & 85 & 85 & 90 \\
\hline
\end{tabular}

${ }^{*}$ Criteria for calculating the NIOSH REL and OSHA AL include all noise exposures greater than or equal to $80 \mathrm{dBA}$.

†Criteria for calculating the OSHA PEL include all noise exposures greater than or equal to $90 \mathrm{dBA}$. 
Table C7. Measured air velocities, smoke evaluation, and recommended flow rates for machines in the carpenter/boat builder shop connected to the local exhaust ventilation system

\begin{tabular}{|c|c|c|c|}
\hline Machine & $\begin{array}{l}\text { Measured air velocities } \\
\text { (feet per minute [fpm]) }\end{array}$ & Smoke evaluation & $\begin{array}{l}\text { Recommended flow rates } \\
\text { (cubic feet per minute [cfm]) }\end{array}$ \\
\hline Band saw & $\begin{array}{l}\text { Very minimal measured } \\
\text { velocities: the damper was } \\
\text { open but exhaust must not } \\
\text { have been connected }\end{array}$ & No real smoke capture & $\begin{array}{l}\text { For blades up to } 3 " \\
\text { 700-900 cfm }\end{array}$ \\
\hline Belt sander & $\begin{array}{c}800-1,300 \mathrm{fpm} \text { around } \\
\text { the belt } \\
\begin{array}{c}1,800-3,000 \text { fpm below the } \\
\text { adjustable work table }\end{array}\end{array}$ & $\begin{array}{l}\text { Very good } \\
\text { smoke capture }\end{array}$ & $\begin{array}{l}\text { Belts up to 6": } 440 \mathrm{cfm} \\
\text { Belts 6"-9": } 550 \mathrm{cfm}\end{array}$ \\
\hline Disc sander & $\begin{array}{l}\text { No ventilation around } \\
\text { disc sander attached to } \\
\text { belt sander }\end{array}$ & $\mathrm{n} / \mathrm{a}$ & $\begin{array}{l}\text { Discs up to } 12 ": 350 \mathrm{cfm} \\
\text { Discs 12"-18": } 440 \mathrm{cfm} \\
\text { Discs 18"-26": } 550 \mathrm{cfm}\end{array}$ \\
\hline Drum sander & $\begin{array}{l}\text { 150-200 fpm at slot } \\
\text { above belt }\end{array}$ & Poor smoke capture & $\begin{array}{l}\text { Drum surface area up to } \\
200 \text { in²: } 350 \mathrm{cfm}^{200-400 \mathrm{in}^{2}: 550 \mathrm{cfm}} \\
400-700 \mathrm{in}^{2}: 790 \mathrm{cfm}\end{array}$ \\
\hline Table saw & $800-1,000 \mathrm{fpm}$ at slot & $\begin{array}{c}\text { Marginal } \\
\text { smoke capture }\end{array}$ & $\begin{array}{l}\text { Blade up to 16": } 545 \mathrm{cfm} \\
\text { Blade over 16": } 785 \mathrm{cfm} \\
\text { Ventilated blade guard: } 100 \mathrm{cfm}\end{array}$ \\
\hline Miter saw & $100-200 \mathrm{fpm}$ at hood & Good smoke capture & $\mathrm{n} / \mathrm{a}$ \\
\hline
\end{tabular}

*We cannot compare the measured air velocities directly to the recommended flow rates. The flow rates are design specifications that can be provided to ventilation engineers in order to ensure that the system meets recommended flow rates derived from the ACGIH Industrial Ventilation: A Manual for Recommended Practice for Design, 29th edition, 2016. 
Table C8. Description of work tasks reported by employees on the questionnaire

\begin{tabular}{lc}
\hline Task & Number of employees $(\mathrm{n}=19)$ \\
\hline Grinding & 15 \\
Metal cutting & 13 \\
Needle gunning & 9 \\
Metal shearing and/or punching & 8 \\
Repairing hydraulic equipment & 7 \\
Soldering & 6 \\
Welding & 5 \\
Brazing & 5 \\
Cleaning out fuel tanks & 5 \\
Fiberglass installation and/or repair & 2 \\
Carpentry & 2 \\
Demolition of boat deck flooring & 2 \\
Electrical repair & 2 \\
Bilge cleaning & 2 \\
Lathing and/or milling & 1 \\
Sanding paint & 1 \\
Filling/removing fluids from equipment & 1 \\
Running diesel engines & 1 \\
\hline
\end{tabular}


Table C9. Primary work location reported by employees on the questionnaire

\begin{tabular}{lc}
\hline Location & Number of employees $(\mathrm{n}=19)$ \\
\hline Boat bay* & 12 \\
Metal shop $\dagger$ & 4 \\
Pipe fitter shop & 2 \\
Machinist shop & 1 \\
\hline
\end{tabular}

* Because the marine mechanic shop was in the boat bay, we included those who reported marine mechanic shop as their primary work location in the boat bay work location.

$\dagger$ Because there was no separation between the welder and ship fitter shops, we grouped those who reported welder shop or ship fitter shop as their primary work location in the metal shop work location.

Table C10. Frequency of hygiene practices reported by employees on the questionnaire $(n=19)$

\begin{tabular}{lccc}
\hline Practice & \multicolumn{3}{c}{ Frequency } \\
\cline { 2 - 4 } & Always & Sometimes & Never \\
\hline Wash hands before eating/drinking/smoking & 16 & 3 & 0 \\
Wash hands before leaving work & 17 & 2 & 0 \\
Eat/drink or store food/drink in work area & 1 & 8 & 10 \\
\hline
\end{tabular}


Table C11. Description of training activities reported by employees on the questionnaire

\begin{tabular}{lc}
\hline Training & Number of employees $(\mathrm{n}=19)$ \\
\hline Workplace hazards & 18 \\
Respirator use & 18 \\
Use of other personal protective equipment & 16 \\
Health effects associated with exposure to workplace hazards & 15 \\
Ways to prevent or reduce exposures to workplace hazards & 15 \\
Safety data sheets for hazardous materials present in the facility & 12 \\
\hline
\end{tabular}

Table C12. Symptoms and health effects occurring at work over the last 3 months reported by employees on the questionnaire

\begin{tabular}{lc}
\hline Symptom or health effect & Number of employees $(\mathrm{n}=19)$ \\
\hline Tinnitus (ringing, roaring, or buzzing in the ears) & 9 \\
Trouble hearing clearly or fully & 9 \\
Dermatitis & 7 \\
Nasal irritation & 4 \\
Chronic cough & 3 \\
Shortness of breath & 2 \\
Wheezing & 1 \\
Nose bleeds & 1 \\
Sinus infections & 1 \\
\hline
\end{tabular}




\section{Section D: Occupational Exposure Limits}

NIOSH investigators refer to mandatory (legally enforceable) and recommended OELs for chemical, physical, and biological agents when evaluating workplace hazards. OELs have been developed by federal agencies and safety and health organizations to prevent adverse health effects from workplace exposures. Generally, OELs suggest levels of exposure that most employees may be exposed to for up to 10 hours per day, 40 hours per week, for a working lifetime, without experiencing adverse health effects. However, not all employees will be protected if their exposures are maintained below these levels. Some may have adverse health effects because of individual susceptibility, a pre-existing medical condition, or a hypersensitivity (allergy). In addition, some hazardous substances act in combination with other exposures, with the general environment, or with medications or personal habits of the employee to produce adverse health effects. Most OELs address airborne exposures, but some substances can be absorbed directly through the skin and mucous membranes.

Most OELs are expressed as a TWA exposure. A TWA refers to the average exposure during a normal 8- to 10-hour workday. Some chemical substances and physical agents have recommended short-term exposure limits or ceiling values. Unless otherwise noted, the short-term exposure limit is a 15-minute TWA exposure. It should not be exceeded at any time during a workday. The ceiling limit should not be exceeded at any time.

In the United States, OELs have been established by federal agencies, professional organizations, state and local governments, and other entities. Some OELs are legally enforceable limits; others are recommendations.

- OSHA, an agency of the U.S. Department of Labor, publishes permissible exposure limits [29 CFR 1910 for general industry; 29 CFR 1926 for construction industry; and 29 CFR 1917 for maritime industry] called PELs. These legal limits are enforceable in workplaces covered under the Occupational Safety and Health Act of 1970.

- NIOSH RELs are recommendations based on a critical review of the scientific and technical information and the adequacy of methods to identify and control the hazard. NIOSH RELs are published in the NIOSH Pocket Guide to Chemical Hazards [NIOSH 2007]. NIOSH also recommends risk management practices (e.g., engineering controls, safe work practices, employee education/training, PPE, and exposure and medical monitoring) to minimize the risk of exposure and adverse health effects.

- Another set of OELs commonly used and cited in the United States include the threshold limit values or TLVs, which are recommended by ACGIH. The ACGIH TLVs are developed by committee members of this professional organization from a review of the published, peerreviewed literature. TLVs are not consensus standards. They are considered voluntary exposure guidelines for use by industrial hygienists and others trained in this discipline "to assist in the control of health hazards" [ACGIH 2019].

Outside the United States, OELs have been established by various agencies and organizations and include legal and recommended limits. The Institut für Arbeitsschutz der Deutschen Gesetzlichen 
Unfallversicherung (Institute for Occupational Safety and Health of the German Social Accident Insurance) maintains a database of international OELs from European Union member states, Canada (Québec), Japan, Switzerland, and the United States. The database, available at https://www.dguv.de/ifa/gestis/gestis-stoffdatenbank/index-2.jsp, contains international limits for more than 2,000 hazardous substances and is updated periodically.

OSHA (Public Law 91-596) requires an employer to furnish employees a place of employment free from recognized hazards that cause or are likely to cause death or serious physical harm. This is true in the absence of a specific OEL. It also is important to keep in mind that OELs may not reflect current health-based information.

When multiple OELs exist for a substance or agent, NIOSH investigators generally encourage employers to use the lowest OEL when making risk assessment and risk management decisions.

\section{Chromium and Hexavalent Chromium}

Chromium metal is a hard, blue-white to steel-gray colored, lustrous, brittle element [NIOSH 2007]. In the environment, it exists primarily in two valence states, trivalent chromium or $\mathrm{Cr}(\mathrm{III})$ and hexavalent chromium or $\mathrm{Cr}(\mathrm{VI})$ [EPA 2000].

Although chromium is an essential trace element in humans, $\mathrm{Cr}(\mathrm{VI})$ is extremely toxic and designated as a human carcinogen [IARC 2012; NIOSH 2013; OSHA 2006]. Cr(VI) is associated with lung cancer and nasal and sinus cancer; nonmalignant respiratory effects include irritated, ulcerated, or perforated nasal septa. The median airborne concentration of $\mathrm{Cr}(\mathrm{VI})$ in a study of U.S. workers, some of whom had nasal ulceration, was $20 \mu \mathrm{g} / \mathrm{m}^{3}$, and the median time from employment to first diagnosis of nasal ulceration was less than a month [Gibb et al. 2000]. The purpose of the NIOSH REL for Cr(VI) compounds is to reduce occupationally exposed workers' risk of lung cancer associated with $\mathrm{Cr}(\mathrm{VI})$ compounds over a 45-year working lifetime. NIOSH further recommends reducing exposures to $\mathrm{Cr}(\mathrm{VI})$ compounds to below the REL to address the residual lung cancer risk that remains in those exposed to $\mathrm{Cr}(\mathrm{VI})$ compounds at the REL. Reducing airborne occupational exposures to $\mathrm{Cr}(\mathrm{VI})$ compounds will also reduce the nonmalignant respiratory effects of $\mathrm{Cr}(\mathrm{VI})$ compounds [NIOSH 2013].

Dermal exposures to $\mathrm{Cr}(\mathrm{VI})$ can result in skin irritation, ulcers, skin sensitization, and allergic contact dermatitis. NIOSH recommends preventing workplace dermal exposure to $\mathrm{Cr}(\mathrm{VI})$ to reduce the risk of adverse dermal effects [NIOSH 2013].

NIOSH RELs for chromium include the NIOSH REL for chromium metal, divalent chromium or $\mathrm{Cr}(\mathrm{II})$, and $\mathrm{Cr}(\mathrm{III})$ compounds of $500 \mu \mathrm{g} / \mathrm{m}^{3}$. The NIOSH REL for all $\mathrm{Cr}(\mathrm{VI})$ compounds is $0.2 \mu \mathrm{g} / \mathrm{m}^{3}$ [NIOSH 2007]. OSHA PELs for chromium and chromium compounds include the OSHA PEL for chromium metal and insoluble salts of $1,000 \mu \mathrm{g} / \mathrm{m}^{3}$ [29 CFR 1910.1000, Table Z-1], the OSHA PEL for $\mathrm{Cr}(\mathrm{II})$ and $\mathrm{Cr}(\mathrm{III})$ compounds of $500 \mu \mathrm{g} / \mathrm{m}^{3}$ [29 CFR 1910.1000, Table Z-1], and the OSHA PEL for $\mathrm{Cr}(\mathrm{VI})$ of $5 \mu \mathrm{g} / \mathrm{m}^{3}$ [29 CFR 1910.1026]. The ACGIH TLV is $50 \mu \mathrm{g} / \mathrm{m}^{3}$ for water soluble Cr(VI) compounds and $10 \mu \mathrm{g} / \mathrm{m}^{3}$ for insoluble $\mathrm{Cr}(\mathrm{VI})$ compounds [ACGIH 2019].

Urinary chromium levels are a measure of total chromium exposure. Total chromium is used as a marker of exposure even in situations where $\mathrm{Cr}(\mathrm{VI})$ is the primary concern. A review of the literature suggests that persons without occupational exposure to chromium or $\mathrm{Cr}(\mathrm{VI})$ often have urine 
chromium levels of $0.22-1.8 \mu \mathrm{g} / \mathrm{L}$ of urine [ATSDR 2012a]. Among persons exposed to Cr(VI) at work, the ACGIH BEI for $\mathrm{Cr}(\mathrm{VI})$ of $25 \mu \mathrm{g} / \mathrm{L}$ is based on the total chromium in a urine sample collected at the end of the shift at the end of the workweek. This BEI is based on the observed correlation with exposure to soluble $\mathrm{Cr}(\mathrm{VI})$ and applies to employees with a history of chronic $\mathrm{Cr}(\mathrm{VI})$ exposure. The ACGIH also has a BEI for $\mathrm{Cr}(\mathrm{VI})$ of $10 \mu \mathrm{g} / \mathrm{L}$ for the increase in total chromium over a single shift when comparing preshift and postshift chromium levels [ACGIH 2019]. OSHA does not have a legal requirement for levels of urine chromium.

\section{Manganese}

Manganese (Mn) metal is a silver-gray colored, lustrous, brittle element [NIOSH 2007]. It forms compounds in multiple oxidation states, but compounds containing the $\mathrm{Mn}(\mathrm{II}), \mathrm{Mn}(\mathrm{III})$, and $\mathrm{Mn}(\mathrm{IV})$ oxidation states are most commonly found in the environment [ATSDR 2012b].

Although some manganese intake is essential for human health, exposure to high levels of manganese is toxic. Work-related inhalation of manganese is the primary source of toxic manganese exposure. Airborne manganese consists primarily of insoluble oxides in particulate form. The most common manifestations of manganese overexposure are neurologic in nature and begin insidiously with feelings of weakness and lethargy. As exposure continues, symptoms such as tremor, speech impairment, and incoordination may occur. A characteristic sign of chronic manganese intoxication is the complete absence of facial expression. In some cases, overexposure to manganese can lead to psychiatric disturbances. Although manganese intoxication resembles Parkinsonism, it can be distinguished clinically and by pathology [ATSDR 2012b].

Subclinical neurological health effects, such as decreased performance on neurobehavioral tests, have also been noted in workers exposed to lower levels of manganese [ATSDR 2012b]. However, results of studies evaluating associations between low manganese exposure levels and neurologic deficits are mixed. For example, a study of manganese alloy plant workers found that manganese-exposed workers had increased hand tremor compared to unexposed controls [Bast-Pettersen et al. 2004]. Other studies have shown poorer performance on neurobehavioral tests, such as finger tapping, digit span, and visual reaction time, among manganese-exposed workers [Lucchini et al. 1995; Roels et al. 1992]. Conversely, other studies have not found an association between low-level occupational manganese exposure and neurologic health effects [Deschamps et al. 2001]. Interpreting abnormal neurobehavioral tests from workplace exposure to low levels of manganese is difficult, and abnormalities found in asymptomatic workers do not necessarily imply progression to disease [Santamaria et al. 2007].

The NIOSH REL for manganese and its compounds is $1 \mathrm{mg} / \mathrm{m}^{3}$, and the NIOSH STEL is $3 \mathrm{mg} / \mathrm{m}^{3}$ [NIOSH 2007]. OSHA does not have a PEL for manganese for full-shift exposures but does have a ceiling limit of $5 \mathrm{mg} / \mathrm{m}^{3}$, which should not be exceeded at any time [29 CFR 1910.1000, Table Z-1]. The ACGIH TLV is $0.2 \mathrm{mg} / \mathrm{m}^{3}$ [ACGIH 2019].

A review of the literature suggests that persons without occupational exposure to manganese often have blood manganese levels of 4-15 $\mathrm{g} / \mathrm{L}$ and urine manganese levels of $1-8 \mu \mathrm{g} / \mathrm{L}$. Several studies have shown higher blood and urine manganese levels in groups of workers who are chronically exposed to airborne manganese at work [ATSDR 2012b]. One study found correlations between blood and urine 
manganese concentrations and airborne manganese cumulative exposure indices [Lucchini et al. 1995]. However, other evidence suggests that blood and urine manganese levels may not be reliable for tracking individual exposure to inhaled manganese [ATSDR 2012b; Smith et al. 2007]. Manganese levels in hair are variable depending on hair color and use of dyes [ATSDR 2012b], and should not be used to follow exposure. Magnetic resonance imaging (MRI) can demonstrate areas of manganese accumulation in the brain [ATSDR 2012b], but using MRI to follow exposure over time is impractical. There are no established OELs in the United States for levels of manganese in the urine.

\section{Nickel}

Nickel metal is a hard, lustrous, silvery-white colored element. It is used in alloys, nickel plating, ceramic coloring, and batteries. Nickel is particularly useful in alloys because of the corrosion and heat resistance, hardness, and strength that it provides [ATSDR 2005].

Although trace amounts of nickel are essential for human health, overexposure to nickel can have harmful effects. Allergic reactions from direct skin contact with nickel, such as development of a rash at the site of the nickel contact, are the most common harmful health effect in humans. More serious harmful health effects have been noted among working populations who are chronically overexposed to nickel. Inhalation of nickel-containing dust and fumes may cause asthma attacks in workers who are sensitized to nickel or may lead to chronic bronchitis or reduced lung function over time [ATSDR 2005]. Nickel is also considered a cancer-causing agent, with chronic overexposures to insoluble nickel compounds leading to nasal, sinus, and lung cancers [ATSDR 2005; IARC 2012].

The NIOSH REL for nickel, based on its designation as a potential occupational lung carcinogen, is $0.015 \mathrm{mg} / \mathrm{m}^{3}$ [NIOSH 2007]. The OSHA PEL for nickel metal and insoluble and soluble nickel compounds is $1 \mathrm{mg} / \mathrm{m}^{3}$ [29 CFR 1910.1000, Table Z-1]. The ACGIH TLV for insoluble compounds (i.e., nickel sulfide and nickel oxide) of nickel is $0.2 \mathrm{mg} / \mathrm{m}^{3}$, for soluble nickel compounds and nickel subsulfide is $0.1 \mathrm{mg} / \mathrm{m}^{3}$, and for elemental nickel is $1.5 \mathrm{mg} / \mathrm{m}^{3}$ [ACGIH 2019]. All the TLVs for nickel are applicable to the inhalable fraction of employee exposures to particulates.

A review of the literature suggests that persons without occupational exposure to nickel often have urine nickel levels of $<4 \mu \mathrm{g} / \mathrm{L}$ [WHO 1996]. Although there are no established OELs in the United States for levels of nickel in the urine, the Finnish Institute of Occupational Health has set a Biomonitoring Action Limit (similar to an ACGIH BEI) for nickel and slightly soluble nickel salts of $5.9 \mu \mathrm{g} / \mathrm{L}(0.1$ micromoles per liter $)$ in a postshift urine sample collected at the end of the workweek.

\section{Noise}

Noise-induced hearing loss (NIHL) is an irreversible condition that progresses with noise exposure. It is caused by damage to the nerve cells of the inner ear and, unlike some other types of hearing disorders, cannot be treated medically [Berger et al. 2003]. More than 22 million U.S. workers are estimated to be exposed to workplace noise levels above $85 \mathrm{dBA}$ [Tak et al. 2009]. NIOSH estimates that workers exposed to an average daily noise level of $85 \mathrm{dBA}$ over a 40 -year working lifetime have an $8 \%$ excess risk of material hearing impairment. This excess risk increases to $25 \%$ for an average daily noise exposure of $90 \mathrm{dBA}$ [NIOSH 1998]. NIOSH defines material hearing impairment as an average of the 
hearing threshold levels for both ears that exceeds $25 \mathrm{~dB}$ at frequencies of 1,000 Hertz (Hz); 2,000 Hz; 3,000 Hz; and 4,000 Hz.

Although hearing ability commonly declines with age, exposure to excessive noise can increase the rate of hearing loss. In most cases, NIHL develops slowly from repeated exposure to noise over time, but the progression of hearing loss is typically the greatest during the first several years of noise exposure. NIHL can also result from short-duration exposures to high noise levels or even from a single exposure to an impulse noise or a continuous noise, depending on the intensity of the noise and the individual's susceptibility to NIHL [Berger et al. 2003]. Noise-exposed workers can develop substantial NIHL before it is clearly recognized. Even mild hearing losses can impair a person's ability to understand speech and hear many important sounds. In addition, some people with NIHL also develop tinnitus. Tinnitus is a condition in which a person perceives sound in one or both ears, but no external sound is present. Persons with tinnitus often describe hearing ringing, hissing, buzzing, whistling, clicking, or chirping like crickets. Tinnitus can be intermittent or continuous and the perceived volume can range from soft to loud. Currently, there is no cure for tinnitus.

The preferred unit for reporting of noise measurements is the $\mathrm{dBA}$. A-weighting is used because it approximates the "equal loudness perception characteristics of human hearing for pure tones relative to a reference of $40 \mathrm{~dB}$ at a frequency of $1,000 \mathrm{~Hz}$ " and is considered to provide a better estimation of hearing loss risk than using unweighted or other weighting measurements [Berger et al. 2003].

Employees exposed to noise should have baseline and yearly hearing tests to evaluate their hearing thresholds and determine whether their hearing has changed over time. Hearing testing should be done in a quiet location, such as an audiometric test booth, where background noise does not interfere with accurate measurement of hearing thresholds. In workplace hearing conservation programs, hearing thresholds must be measured at $500 \mathrm{~Hz} ; 1,000 \mathrm{~Hz} ; 2,000 \mathrm{~Hz} ; 3,000 \mathrm{~Hz} ; 4,000 \mathrm{~Hz}$; and 6,000 Hz. Additionally, NIOSH recommends testing at 8,000 Hz [NIOSH 1998].

The OSHA hearing conservation standard requires analysis of changes from baseline hearing thresholds to determine if the changes are substantial enough to meet OSHA criteria for an STS. OSHA defines an STS as a change in hearing threshold (relative to the baseline hearing test) of an average of $10 \mathrm{~dB}$ or more at 2,000 Hz; 3,000 Hz; and 4,000 Hz in either ear [29 CFR 1910.95]. If an STS occurs, the company must determine if the hearing loss also meets the requirements to be recorded on the OSHA Form 300 Log of Work-Related Injuries and Illnesses [29 CFR 1904.1]. In contrast to OSHA, NIOSH defines an STS as a change in the hearing threshold level of $15 \mathrm{~dB}$ or more (relative to the baseline hearing test) at any test frequency in either ear measured twice in succession [NIOSH 1998].

The NIOSH REL for noise is $85 \mathrm{dBA}$, as an 8-hour TWA. For calculating exposure limits, NIOSH uses a 3-dB time/intensity trading relationship, or exchange rate. Using the NIOSH criterion, an employee can be exposed to $88 \mathrm{dBA}$ for no more than 4 hours, $91 \mathrm{dBA}$ for 2 hours, $94 \mathrm{dBA}$ for 1 hour, $97 \mathrm{dBA}$ for 0.5 hours, etc. Exposure to impulsive noise should never exceed $140 \mathrm{dBA}$. For extended work shifts, NIOSH adjusts the REL to $84.5 \mathrm{dBA}$ for a 9-hour shift, $84.0 \mathrm{dBA}$ for a 10-hour shift, 83.6 dBA for an 11-hour shift, and 83.2 dBA for a 12-hour work shift. NIOSH recommends the use of hearing protection and the implementation of a hearing loss prevention program when noise exposures exceed the REL [NIOSH 1998]. 
The OSHA noise standard specifies a PEL of $90 \mathrm{dBA}$ and an AL of $85 \mathrm{dBA}$, both as 8-hour TWAs. OSHA uses a less conservative 5-dB exchange rate for calculating the PEL and AL. Using the OSHA criterion, an employee may be exposed to noise levels of $95 \mathrm{dBA}$ for no more than 4 hours, $100 \mathrm{dBA}$ for 2 hours, $105 \mathrm{dBA}$ for 1 hour, $110 \mathrm{dBA}$ for 0.5 hours, etc. Exposure to impulsive or impact noise must not exceed $140 \mathrm{~dB}$ peak noise level. OSHA does not adjust the PEL for extended work shifts. However, the $\mathrm{AL}$ is adjusted to $84.1 \mathrm{dBA}$ for a 9-hour shift, $83.4 \mathrm{dBA}$ for a 10-hour shift, $82.7 \mathrm{dBA}$ for an 11-hour shift, and $82.1 \mathrm{dBA}$ for a 12-hour work shift. OSHA requires implementation of a hearing conservation program when noise exposures exceed the AL [29 CFR 1910.95]. 


\section{Section E: References}

\section{Metals}

ACGIH [2019]. 2019 TLVs $^{\circledR}$ and BEIs ${ }^{\circledR}$ : threshold limit values for chemical substances and physical agents and biological exposure indices. Cincinnati, $\mathrm{OH}$ : American Conference of Governmental Industrial Hygienists.

ATSDR [2005]. Toxicological profile for nickel. Atlanta, GA: U.S. Department of Health and Human Services, https://www.atsdr.cdc.gov/toxprofiles/tp15.pdf.

ATSDR [2012a]. Toxicological profile for chromium. Atlanta, GA: U.S. Department of Health and Human Services, https://www.atsdr.cdc.gov/toxprofiles/tp7.pdf.

ATSDR [2012b]. Toxicological profile for manganese. Atlanta, GA: U.S. Department of Health and Human Services, https://www.atsdr.cdc.gov/toxprofiles/tp151.pdf.

Bast-Pettersen R, Ellingsen DG, Hetland SM, Thomassen Y [2004]. Neuropsychological function in manganese alloy plant workers. Int Arch Occup Environ Health 77(4):277-287, https://doi.org/10.1007/s00420-003-0491-0.

Boysen M, Solberg LA, Torjussen W, Poppe S, Høgetveit AC [1984]. Histological changes, rhinoscopical findings and nickel concentration in plasma and urine in retired nickel workers. Acta OtoLaryngol 97(1-2):105-115, https://doi.org/10.3109/00016488409130970.

Deschamps FJ, Guillaumot M, Raux S [2001]. Neurological effects in workers exposed to manganese. J Occup Environ Med 43(2):127-132, https://doi.org/10.1097/00043764-200102000-00011.

EPA [2000]. Chromium compounds. Washington, DC: U.S. Environmental Protection Agency, https://www.epa.gov/sites/production/files/2016-09/documents/chromium-compounds.pdf.

Finnish Institute of Occupational Health [2017]. Biomonitoring of exposure to chemicals. Helsinki, Finland: Finnish Institute of Occupational Health, Biomonitoring services, https://www.ttl.fi/wpcontent/uploads/2017/11/Biomonitoring-of-exposure-to-chemicals-Guideline-for-specimencollection.pdf.

Gibb HJ, Lees PG, Pinsky PF, Rooney BC [2000]. Clinical findings of irritation among chromium chemical production workers. Am J Ind Med 38(2):127-131, https://doi.org/10.1002/10970274(200008)38:2<127::aid-ajim2>3.3.co;2-h.

IARC [2012]. IARC monographs on the evaluation of the carcinogenic risks to humans. A review of human carcinogens: arsenic, metals, fibres, and dusts. Vol. 100C. Lyon, France: World Health Organization, International Agency for Research on Cancer, pp. 147-168, https://monographs.iarc.fr/iarc-monographs-on-the-evaluation-of-carcinogenic-risks-to-humans-19/.

Lucchini R, Selis L, Folli D, Apostoli P, Mutti A, Vanoni O, Iregren A, Alessio L [1995]. Neurobehavioral effects of manganese in workers from a ferroalloy plant after temporary cessation of exposure. Scand J Work Environ Health 21(2):143-149, https://doi.org/10.5271/sjweh.1369. 
NIOSH [2007]. NIOSH pocket guide to chemical hazards. Cincinnati, OH: U.S. Department of Health and Human Services, Centers for Disease Control and Prevention, National Institute for Occupational Safety and Health, DHHS (NIOSH) Publication No. 2005-149, http://www.cdc.gov/niosh/npg/.

NIOSH [2013]. Criteria for a recommended standard: occupational exposure to hexavalent chromium. Cincinnati, OH: U.S. Department of Health and Human Services, Centers for Disease Control and Prevention, National Institute for Occupational Safety and Health, DHHS (NIOSH) Publication No. 2013-128, https://www.cdc.gov/niosh/docs/2013-

128/pdfs/2013 128.pdf?id=10.26616/NIOSHPUB2013128.

NIOSH [2019]. NIOSH manual of analytical methods (NMAM). 5th ed. O’Connor PF, Ashley K, eds. Cincinnati, OH: U.S. Department of Health and Human Services, Centers for Disease Control and Prevention, National Institute for Occupational Safety and Health, DHHS (NIOSH) Publication No. 2014-151, http://www.cdc.gov/niosh/nmam.

OSHA [2006]. OSHA fact sheet: health effects of hexavalent chromium. Washington, DC: U.S. Department of Labor, Occupational Safety and Health Administration, https://www.osha.gov/OshDoc/data General Facts/hexavalent chromium.html.

Roels HA, Ghyselen P, Buchet JP, Ceulemans E, Lauwerys RR [1992]. Assessment of the permissible exposure level to manganese in workers exposed to manganese dioxide dust. Occup Environ Med 49(1):25-34, https://doi.org/10.1136/oem.49.1.25.

Santamaria AB, Cushing CA, Antonini JM, Finley BL, Mowat FS [2007]. State-of-the-science review: does manganese exposure during welding pose a neurological risk? J Toxicol Environ Health, Part B 10(6):417-465, https://doi.org/10.1080/15287390600975004.

Smith D, Gwiazda R, Bowler R, Roels H, Park R, Taicher C, Lucchini R [2007]. Biomarkers of Mn exposure in humans. Am J Ind Med 50(11):801-811, https://doi.org/10.1002/ajim.20506.

Sunderman FW Jr, Aitio A, Morgan LG, Norseth T [1986]. Biological monitoring of nickel. Toxicol Ind Health 2(1):17-78, https:// doi.org/10.1177/074823378600200102.

WHO [1996]. Biological monitoring of chemical exposure in the workplace: guidelines. Vol. 2. Geneva, Switzerland: World Health Organization, http://apps.who.int/iris/bitstream/handle/10665/41856/WHO HPR OCH 96.1.pdf;jsessionid=261 BF726C5209B19F0B5B86FBA2108C6? sequence $=1$.

\section{Noise}

Berger EH, Royster LH, Royster JD, Driscoll DP, Layne M, eds. [2003]. The noise manual. 5th rev. ed. Fairfax, VA: American Industrial Hygiene Association.

Costa-Guarisco LP, Dalpubel D, Labanca L, Chagas MHN [2017]. Perception of hearing loss: use of the subjective faces scale to screen hearing among the elderly. Cien Saude Colet 22(11):3579-3588, https://doi.org/10.1590/1413-812320172211.277872016.

Kamil RJ, Genther DJ, Lin FR [2015]. Factors associated with the accuracy of subjective assessments of hearing impairment. Ear Hear 36(1):164-167, https://doi.org/10.1097/aud.0000000000000075. 
Martines F, Bentivegna D, Martines E, Sciacca V, Martinciglio G [2010]. Assessing audiological, pathophysiological and psychological variables in tinnitus patients with or without hearing loss. Eur Arch Otorhinolaryngol 267(11):1685-1693, https://doi.org/10.1007/s00405-010-1302-3.

NIOSH [1998]. Criteria for a recommended standard: occupational noise exposure (revised criteria 1998). Cincinnati, OH: U.S. Department of Health and Human Services, Centers for Disease Control and Prevention, National Institute for Occupational Safety and Health, DHHS (NIOSH) Publication No. 98-126, http://www.cdc.gov/niosh/docs/98-126/pdfs/98-126.pdf.

Savastano M [2008]. Tinnitus with or without hearing loss: are its characteristics different? Eur Arch Otorhinolaryngol 265(11):1295-1300, https://doi.org/10.1007/s00405-008-0630-z.

Steinmetz LG, Zeigelboim BS, Lacerda AB, Morata TC, Marques JM [2009]. The characteristics of tinnitus in workers exposed to noise. Braz J Otorhinolaryngol 75(1):7-14, https://doi.org/10.1016/s1808-8694(15)30825-9.

Tak S, Davis RR, Calvert GM [2009]. Exposure to hazardous workplace noise and use of hearing protection devices among U.S. workers-NHANES, 1999-2004. Am J Ind Med 52(5):358-371, http://dx.doi.org/10.1002/ajim.20690.

\section{Other}

CFR. Code of Federal Regulations. Washington, DC: U.S. Government Printing Office, Office of the Federal Register, https://www.ecfr.gov/cgi-bin/ECFR?page=browse.

Claeson A, Lidén E, Nordin M, Nordin S [2013]. The role of perceived pollution and health risk perception in annoyance and health symptoms: a population based study of odorous air pollution. Int Arch Occup Environ Health 86(3):367-374, https://dx.doi.org/10.1007/s00420-012-0770-8.

Kain J, Jex S [2010]. Karasek's job demands-control model: a summary of current issues and recommendations for future research. In: Perrewé PL, Ganster DC, eds. New developments in theoretical and conceptual approaches to job stress (Research in occupational stress and well-being). Vol. 8. Bingley, UK: Emerald Books, pp. 237-268, https://doi.org/10.1108/s1479$\underline{3555(2010) 0000008009}$. 


\section{Delivering on the Nation's promise: Promoting productive workplaces through safety and health research}

Get More Information

Find NIOSH products and get answers to workplace safety and health questions:

1-800-C DC-INFO (1-800-232-4636) | TTY: 1-888-232-6348

CDC/NIOSH INFO: cdc.gov/info | cdc.gov/niosh

Monthly NIOSH eNews: cdc.gov/niosh/eNews 